NBER WORKING PAPERS SERIES

\title{
A THEORY OF CORPORATE FINANCIAL STRUCTURE BASED ON THE SENIORITY OF CLAIMS
}

\section{Oliver Hart}

John Moore

Working Paper No. 3431

\author{
NATIONAL BUREAU OF ECONOMIC RESEARCH \\ 1050 Massachusetts Avenue \\ Cambridge, MA 02138 \\ September 1990
}

\footnotetext{
We are grateful to the National Science Foundation, the LSE Suntory-Toyota International Centre for Economics and Related Disciplines, the Olin Foundation, and the Center for Energy Policy Research at MIT for financial support. We would also like to thank Rabindran Abraham, Dick Brealey, Lucien Bebchuk, Stu Myers, David Webb, and participants in the conference on "Financial Contracting and The Theory of the Firm," Paris, June, 1990, for helpful comments. They are, of course, not responsible for the views expressed here. Any opinions expressed are those of the authors and not those of the National Bureau of Economic Research.
} 
NBER Working Paper \#3431

September 1990

\title{
A THEORY OF CORPORATE FTNANCIAL STRUCTURE BASED ON THE SENIORITY OF CIATMS
}

\begin{abstract}
We develop a theory of optimal capital structure based on the idea that debt and equity differ in their priority status relative to future corporate cash payments. A company with high (dispersed) debt will find it hard to raise new capital since new security-holders will have low priority relative to existing senior creditors. Conversely for a campany with low debt. We show that there is an optimal debt-equity ratio and mix of senior and junior debt for a corporation whose management may undertake unprofitable as well as profitable investments. Among other things, our theory can explain the observation that profitable firms have low debt. In addition, it predicts that (long-term) debt will be high if new investment is risky and on average profitable, or if assets in place are risky and new investment is on average unprofitable.
\end{abstract}

Oliver Hart Department of Economics E-52

Massachusetts Institute of Technology 80 Memorial Drive Cambridge, MA 02139
John Moore

Department of Econamics London School of Economics Houghton Street London WC2A $2 \mathrm{AE}$ England 


\section{Introduction}

Since the time of Modigliani and Miller's famous irrelevance theorem, economists have devoted much effort to relaxing the theorem's assumptions in order to understand the real-world trade-offs between debt, equity and other corporate financial instruments. In particular, literatures have developed that explain financial structure as an attempt to reduce taxes (see, e.g., Modigliani and Miller (1963) and Miller (1977)); as a signaling device (see. e.g., Leland-Pyle (1977) and Ross (1977)); as a bonding device (see, e.g., Grossman-Hart (1982) and Jensen (1986)); as a way of completing markets (see, e.g.. Stiglitz (1974) and Allen-Gale (1988)); or as a device for dividing up control rights between various claimant groups (see, e.g., Aghion-Bolton (1988), Hart-Moore (1989), Bolton-Scharfstein (1990), Diamond (1989), Harris-Raviv (1989) and Zender (1989)).

While each of these approaches has provided useful insights, none has been entirely successful in explaining the cholce of financial structure. On the one hand, the tax, signaling and bonding theories all rely on an exogenous cost of bankruptcy to explain why firms are not 100 \& debt-financed. ${ }^{l}$ Not only is this theoretically unsatisfactory, but also, given that estimated bankruptcy costs are not that high (see Warner (1977)), it is unclear whether these theories can explain observed debt-equity ratios. On the other hand, while market completion theories are consistent with high debt-equity ratios, they do not explain the widespread use of debt and equity, as opposed to more complex contingent securities, or why financial intermediaries issuing derivative securities on corporations cannot complete the market instead of the corporations themselves. ${ }^{2}$ Finally, recent control theories do go some way toward explaining the costs of bankruptcy or default and hence the disadvantages of high debt, but most deal with entrepreneurial firms and do not analyze the choice between public debt and public equity. ${ }^{3}$

In this paper, we take a different, and we believe new, approach to understanding corporate financial structure. We argue that an important aspect of any claim issued by a corporation is its senfority or priority status with regard to future corporate cash payments. For example, debt has priority over equity in the sense that if the corporation owes creditors $\$ 100$ and has $P$ dollars to pay out, then creditors must be paid off first, so that 
equity-holders receive something only if $P>100$. In the same way, senior debt has priority over junior (or subordinated) debt in the sense that junior creditors receive something only after senior creditors have been fully paid off.

We argue that the priority structure of a firm's existing claims will be important if the firm needs to return to the market in the future to raise funds for further investment. Suppose at one extreme that the firm is initially 1008 equity financed. Then raising funds for further investment will be relatively easy since the firm can issue debt to the new claim-holders, thus putting them first in line for any future payment. Since claim-holders are prepared to pay for this attractive priority position, the likelihood that the firm can carry out the new investment project is high.

At the other extreme, if the firm has a large amount of (dispersed) initial senior long-term debt, any new claimants will be junior to existing claim-holders (the senior creditors) and so the expected return on new claims will be relatively low. Hence raising new funds will be hard and it is less likely that the firm will be able to carry out the new investment project.

In a world where management cannot be trusted always to make the right investment decisions, either because it is incompetent or because it has objectives of its own, there is an optimal balance between making further investment too easy or too hard. (In the formal model of the paper, we assume that management is self-interested, rather than incompetent.) We use this idea to analyze the corporation's optimal initial financial structure, and in particular the choice between (long-term) debt and equity. Our analysis throws light not only on the debt-equity ratio of a corporation, but also on the mix between different seniorities of debt. Our framework also provides a clear-cut distinction between debt and equity: equity is a "soft" claim in the sense that new claims can be created senior to it; while (senior) debt is a "hard" claim in the sense that new claims can only be created junior to it.

We can illustrate the main idea of the paper using a simple example. Suppose that a firm has assets in place which yield a return of $\$ 200$ at date 
2 If the state of the world is good and $\$ 100$ if the state is bad. Assume that the state becomes known at date 1 , at which time a new investment project becomes available. This project costs $\$ 20$ and boosts date 2 earnings by $\$ 30$ in the good state and by $\$ 10$ in the bad state (for simplicity, take the interest rate to be zero).

Obviously security-holders want the manager to undertake the project in the good state (when it increases net present value, NPV) but not in the bad state. This can be achieved by having initial long-term debt which promises $\$ 100$ at date 2. Then in the bad state the manager cannot finance the project since he (or she) needs to raise $\$ 20$, but can offer new security-holders only $\$ 10$ (the total return of $\$ 110$ minus $\$ 100$ owed initial creditors). On the other hand, the manger has no difficulty financing the project in the good state, since he can offer new security-holders up to $\$(200+30-100)$ at date 2 in return for their $\$ 20$.

Three points should be noted about this example. First, without initial long-term debt, the manager will be able to invest in the bad state as well as the good state since he can offer new date 1 security-holders up to $\$(100+10)$ at date 2 . Second, long-term debt constrains management in the bad state even though (a) it is riskless (the creditors recelve $\$ 100$ in both states of the world); (b) equity has positive value before the state of the world is realized (in the good state equity holders recelve $\$ 110$ ). In other words, the observation that many firms have riskless (or close to riskless) debt and positive equity value is quite consistent with our theory. Finally, in the example, there is no cost to raising the debt level above $\$ 100$ (as long as it is below $\$ 210$ ). However, if we suppose that in the bad state there are sometimes positive NPV projects of arbitrarily small profitability, then a debt level greater than $\$ 100$ will prevent some of these positive NPV projects from being undertaken, and hence is undesirable. ${ }^{4,5}$

There are some similarities between our analysis and that of Myers (1977). Like us, Myers develops a theory of financlal structure based on the distinction between assets in place and further investment. In Myers' model, a large level of debt is costly because it causes firms, which are supposed to act on behalf of initial shareholders, to pass up profitable projects, since much of the benefit from these projects accrues to creditors rather 
than shareholders. Firms trade off these costs against the tax benefits of debt.

Myers' analysis begs the question of why management acts on behalf of initial shareholders. If management is prepared to act on behalf of an outside group at all, i.e. It is not self-interested, why could it not be encouraged to act on behalf of shareholders and creditors as a whole, thus apparently removing the costs of debt finance (after all, individual investors who diversify may hold a combination of debt and equity anyway)? ${ }^{6}$ In contrast, we assume that management is self-interested and so cannot be made to act on behalf of any group except itself. In our model, the cost of debt is not that management passes up profitable projects because they are not in the interest of shareholders, but rather that management cannot finance profitable projects that are in the collective interest of shareholders and creditors. 7

Our model also has parallels to Jensen's free cash flow hypothesis (see, e.g., Jensen (1986)). Jensen has argued that managers will use retained earnings to finance negative present value investment projects unless forced to pay these earnings out to investors. Jensen sees debt as a way to make management disgorge funds since, if management fails to meet interest payments and defaults, creditors can force the firm into bankruptcy. Jensen's theory does not, however, explain the costs of debt, 1.e. why corporations are not 100 debt-financed.

Our model differs from Jensen's in that we analyze the role of financial structure in controlling the flow of funds into the firm rather than the flow of funds out of the firm. That is, in our model high debt is good (or bad) because it makes it difficult for the firm to raise further funds in the future; we ignore the threat of bankruptcy or liquidation in forcing the firm to pay out funds.

We proceed in this way for three reasons. First, to model bankruptcy and liquidation requires dealing with a complex set of issues distinct from those analyzed here; we hope to explore these in a subsequent paper. 8 Second, there are a number of situations in which the threat of bankruptcy or liquidation - even if effective - is unlikely to change our results. Our 
analysis applies in particular to a firm which needs cash in the short-run to finance long-term projects. For such a firm there is no obvious role for short-term debt as a means of getting cash out of the corporation; however, there is a role for long-term debt to control the flow of funds into the corporation.

Finally, in practice, the threat of bankruptcy may be less powerful in forcing corporations to disgorge funds than is sometimes thought. In the United States, management can usually put a corporation into Chapter 11 and continue to manage the corporation's assets, keeping creditors at bay, for long periods of time (particularly if the liquidation value of the assets is low relative to the going concern value). Furthermore, to the extent that dispersed creditors become the new (dispersed) shareholders in the corporation, it is unclear why they should have a greater ability to control the disbursement of funds during or post-bankruptcy than dispersed shareholders and creditors did pre-bankruptcy. Thus a model which ignores the disciplinary role of bankruptcy may be of practical as well as theoretical interest. 9

The paper is organized as follows. The model is laid out in section 2. Section 3 characterizes optimal financial structure and derives a number of comparative statics results concerning the relationship between a firm's optimal debt/equity ratio and the mean and variance of the return on assets in place and on new investments. Among other things, we show that our theory is consistent with "the two most striking facts about corporate finance" (see Myers (1990)): profitability and financial leverage are negatively correlated, and increases in leverage raise market value. Conclusions follow in Section 4 . 


\section{The Model}

We consider a three-date model in which a corporation's security structure is chosen at date 0 , an investment decision is made by management at date 1, and funds are paid out to investors at date 2 (see Figure 1).

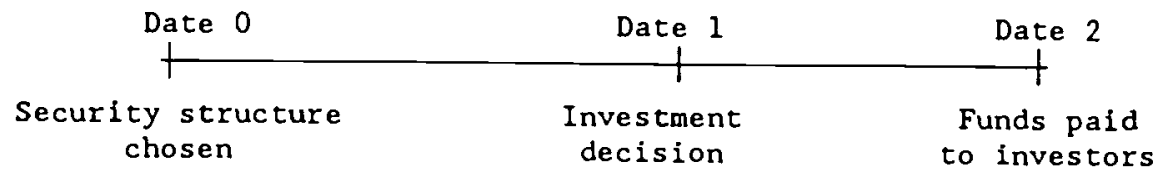

Figure 1

To simplify we assume that the investment decision is zero-one: either the manager invests a given amount $i$ in an investment project, or he invests nothing. If he invests, the project realizes a return at date 2 equal to $r$. In addition, the firm is supposed to have assets already in place, which yield a return equal to $y_{1}$ at date 1 and $y_{2}$ at date 2 . Any part of $y_{1}$ which is not used for physical investment is supposed to be saved in the firm at the going rate of interest (rather than being paid out to security-holders at date 1). For simplicity, we take this interest rate to be zero over the whole horizon from date 0 to date 2.10

As emphasized in the Introduction, we are interested in a situation where management may carry out some investment projects for power or empire-building reasons even though they are unprofitable (as in Marris (1964) or Jensen (1986); see Donaldson (1984) for empirical support for this hypothesis). To simplify, we consider the extreme case where the empire-building motive is so strong that no ordinary financial incentive or disincentive (e.g. stock options) can deter the manager from investing at date 1. Hence the only way to stop him from investing is to prevent the necessary funds from being made available at this date. In contrast, we suppose that at date 2 there are no investment opportunities and so the manager is willing to pay out all accumulated funds (one interpretation is that the firm is 1 iquidated at date 2 ; note that we assume that the manager cannot abscond with the date 2 funds). 
As also emphasized in the Introduction, we abstract from any role that the date 0 security structure might have in forcing the manager to disgorge funds at date 1. Formally, we suppose that even if the manager has promised creditors a sum of money at date 1 , he can always default, and carry on running the firm (and investing) in bankruptcy with the same date 2 financial structure. $^{11}$ Note that our analysis applies in particular to a firm which always needs cash in the short-run ( $1 . e . y_{1}<1$ at date 1); the reader uncomfortable with our treatment of bankruptcy may wish to focus on this case, where there would be no obvious advantage to having debt due at date 1 , even if this did force the manager to pay out funds.

To recap, the firm's situation is characterized by four variables ( $y_{1}$, $\left.y_{2}, i, r\right)$. As of date 0 , these variables are uncertain. For simplicity, we assume that this uncertainty is completely resolved at date 1 and $y_{1}, y_{2}, r$, 1 , become common knowledge at this date, $1 . e$. there is no asymmetry of information between management and the market. (of course, the date 1 return $y_{1}$ must be determined at date 1 ; we suppose that $y_{2}, r$ and 1 become known as well.) However, although $y_{1}, y_{2}, 1, r$ are observable at date 1 , they are not verifiable. $^{12}$ Finally, we suppose that the probability distribution $F\left(y_{1}, y_{2}, 1, r\right)$ is common knowledge at date 0 ; and that $y_{1}, y_{2}, 1, r$ have finite supports.

\section{Security Structure}

Although $y_{1}, y_{2}, i, r$ are not verifiable, we suppose that the total amount paid out to security-holders at date 2 , denoted by $P$, is verifiable. Thus securities can be issued at date 0 with claims conditional on $P$. Examples are a class of bonds with a promised total repayment of 100 (the bonds pay 100 if $P \geq 100$, and $P$ otherwise); and a class of common shares, which pays $\mathrm{P}$ minus any payments to creditors.

We suppose that any securities issued by the firm are held by a large number of small investors who are risk-neutral with respect to the firm's return (e.g. because it is idiosyncratic). ${ }^{13}$ Given that the securities are widely dispersed, any attempt by the firm to renegotiate these securities at 
a later date is likely to be extremely difficult because of hold-out and free-rider problems. In fact, we assume that such renegotiation is impossible (we return to this issue in the Conclusions).

Given our assumptions about verifiability and impossibility of renegotiation, the most general security structure consists of contingent debt, along the following lines. The firm issues a single class of securities at date $O$ with an (enforceable) promise that if $P$ dollars are distributed at date 2 , this class will collectively receive $O(P)$ of them, where $0 \leq O(P) \leq P$. (The " $O$ " in $O(P)$ denotes the old, or original, date 0 security holders.) In addition, management is given permission to issue any new securities it likes at date 1 . That is, management can earmark the residual amount $N(P)=(P-O(P))$ for new investors at date 1 in the attempt to finance new investment. (The "N" in $N(P)$ denotes the new investors at date 1.) Note that a choice of $O(P)$ close to or far away from $P$ at date 0 constrains the firm more or less in its investment choice at date 1 .

Securities defined in precisely this way are not, to our knowledge, observed. However, we show shortly that, under two mild assumptions, any choice of $O(P)$ is equivalent to a package of "standard" securities, consisting of equity and various seniorities of debt. Thus for the moment we stick with the general specification $O(P)$.

Given $N($.$) (or equivalently O($.$) ), consider the position of management$ at date 1 once $\left(y_{1}, y_{2}, i, r\right)$ are realized. If $y_{1} \geq i$, the manager will obviously invest since he can finance this out of retained earnings: he does not have to go to the market at all. The total pay-out to investors at date 2 will be $P-y_{1}-i+y_{2}+r$, consisting of $y_{2}$ from the old assets, $r$ from the new project and $y_{1}-i$ from the saving of date 1 retained earnings.

If $y_{1}<i$, the manager can invest only if he can raise $\left(i-y_{1}\right)$ from the market. If he does invest, $P-r+y_{2}$ (there are no retained earnings at date 1$)$, and so the most he can offer the market at date 2 is $N\left(r+y_{2}\right)$. Given a zero interest rate, it follows that the manager will be able to finance the investment if and only if $\mathrm{N}\left(\mathrm{r}+\mathrm{y}_{2}\right) \geq \mathrm{i}-\mathrm{y}_{1}$. (Recall that $r+y_{2}$ is known at date 1.) Assuming this inequality holds, we suppose that the manager offers new security-holders at date 1 exactly $\left(i-y_{1}\right)$ at date 2 
so that they break even. The amount left for initial security holders at date 2 is therefore $\left(x+y_{2}\right)-\left(i-y_{1}\right)-y_{1}+y_{2}+r-1$.

We may summarize the above discussion as follows:

(a) If $y_{1} \geq i$, investment occurs, $P-r+y_{1}+y_{2}-i$ and the return to initial security-holders is $y_{1}+y_{2}+r-i$. If $\mathrm{y}_{1}<\mathrm{i}$ and $\mathrm{N}\left(\mathrm{r}+\mathrm{y}_{2}\right) \geq \mathrm{i}-\mathrm{y}_{1}$, investment occurs, $\mathrm{P}-\mathrm{r}+\mathrm{y}_{2}$ and the return to initial security-holders is $y_{1}+y_{2}+r-i$.

(c) If $y_{1}<i$ and $\mathrm{N}\left(\mathrm{r}+\mathrm{y}_{2}\right)<\mathrm{i}-\mathrm{y}_{1}$, investment does not occur, $P=y_{1}+y_{2}$ and the return to initial security-holders is $y_{1}+y_{2}$.

We assume that the security structure is chosen at date 0 to maximize the firm's total market value, i.e. the expected return to the initial security holders. This assumption can be justified in two ways. First, the firm may be owned prior to date 0 by a single large investor who wants to "get out" and selects the initial security structure to maximize his wealth. Second, one can imagine that the firm consists entirely of (dispersed) equity prior to date 0 , but that the firm is subject to a hostile takeover at this date and management is forced to restructure the firm to maximize the market value of equity in order to stay in control. 14

Subtracting $\mathrm{y}_{1}+\mathrm{y}_{2}$ from the initial security-holders' return in cases (a) - (c); and using the fact that $y_{1} \geq i \Rightarrow N\left(r+y_{2}\right) \geq i-y_{1}$ to combine cases (a) and (b); we may define an optimal security structure as follows.

Definition. An opeimal security structure at date 0 is represented by a function $N(P)$, which solves: 


$$
\begin{aligned}
& \underset{N(.)}{\operatorname{Maximize}} \int_{N\left(r+y_{2}\right) \geq i-y_{1}}(r-i) d F\left(y_{1}, y_{2}, i, r\right) \\
& \text { subject to } \\
& 0 \leq N(P) \leq P .
\end{aligned}
$$

So far we have allowed the slope of $N(P)$ to be almost arbitrary. With a minor modification in the manager's set of available actions, however, we can restrict $N$ to have a slope between zero and one. Recall that $y_{1}, y_{2}, r$, $i$ have finite support and so $P$ takes on finitely many values, say $P_{1}<P_{2} \cdots$ $<P_{n}$. Assume that the manager can commit himself at date 1 to lower the return both of the investment project and of the assets in place, e.g. by selling off some fraction of the assets at an artificially low price or by hiring extra workers. Suppose $P_{j}<P_{k}$ and $N\left(P_{j}\right)>N\left(P_{k}\right)$ for some $j<k$. Then the firm's date 0 market value can only increase if $N\left(P_{k}\right)$ is raised to equal $N\left(P_{j}\right)$. The reason is that the low value of $N\left(P_{k}\right)$ cannot be effective in deterring management from investing, since if $\mathrm{y}_{2}+\mathrm{r}-\mathrm{P}_{\mathrm{k}}$ and $\mathrm{N}\left(\mathrm{P}_{\mathrm{k}}\right)<i-\mathrm{y}_{1}$ $\leq N\left(P_{j}\right)$, the manager will raise the (i - $y_{1}$ ) dollars necessary to invest by committing himself to lower total return from $P_{k}$ to $P_{j}$. Thus if $N\left(P_{k}\right)$ is raised to $N\left(P_{j}\right)$, the same investment decisions occur but total return is generally higher since the manager is not encouraged to engage in wastage. An extension of this argument shows that date 0 market value can only increase if $N\left(P_{j}\right)$ is replaced by $\max _{\ell \leq j} N\left(P_{\ell}\right)$ for each $j$. This yields a monotonically increasing $\mathrm{N}$.

A similar argument shows that the slope of $\mathrm{N}$ can be set less than or equal to one, if the manager can always raise more funds than he needs for the investment project and save the rest at the going rate of interest. Suppose $P_{j}<P_{k}$ and $N\left(P_{k}\right)-N\left(P_{j}\right)>P_{k}-P_{j}$. Then the firm's date 0 market value will not change if $N\left(P_{j}\right)$ is raised to $N\left(P_{k}\right)-P_{k}+P_{j}$. The reason is that if $\mathrm{y}_{2}{ }^{+}$ $r-P_{j}$ and $N\left(P_{j}\right)<i-y_{1} \leq N\left(P_{k}\right)-P_{k}+P_{j}$, the manager can raise $\left(i-y_{1}\right)+$ $\left(P_{k}-P_{j}\right)$ dollars from the market, invest $i$ in the project and save the 
remaining $\left(\mathrm{P}_{\mathrm{k}}-\mathrm{P}_{\mathrm{j}}\right)$. This yields a total date 2 return of $\mathrm{P}_{k}$, out of which the manager can repay new security-holders up to $N\left(P_{k}\right) \geq 1-y_{1}+\left(P_{k}-P_{j}\right)$. Again this argument can be extended to show that date 0 market value will be unchanged if $N\left(P_{j}\right)$ is replaced by $\max _{k \geq j}\left(N\left(P_{k}\right)-P_{k}+P_{j}\right)$. This yields an $N$ whose slope is less than or equal to one.

From now on, therefore, we assume that $\mathrm{N}$ has slope between 0 and 1 . In particular, we impose the extra constraint

$$
P_{j} \leq P_{k} \rightarrow N\left(P_{j}\right) \leq N\left(P_{k}\right) \leq N\left(P_{j}\right)+P_{k}-P_{j} \text { for all } j, k
$$

$$
\text { or } 0 \leq \frac{\Delta N(P)}{\Delta P} \leq 1
$$

when we solve for optimal security structure.

\section{Representing $\mathrm{O}$ or $\mathrm{N}$ by a Standard Package of Securities}

We now show that any function $N$ satisfying (2.2)-(2.3) can be implemented by an appropriate package of standard securities - - in particular, equity and noncontingent debt of various seniorities.

Let us begin by defining standard noncontingent debt and equity.

Definition. A standard package of debt and equity consists of $n$ classes of debt and a single class of equity. The $j$ th class of debt, $j-1, \ldots, n$, is characterized by an amount $d_{j}$ collectively owed to class $j$ at date 2 and a maximum additional amount $\Delta d_{j}$ of indebtedness to class $j$ that the firm can take on at date 1 (i.e. a covenant in the initial debt contract allows the firm to issue new debt at date 1 until the total amount owed class $i$ is $d_{j}+$ $\Delta d_{j}$ ). The classes are ranked by seniority with 1 being the most senior (in the sense that it must be paid off first) and $n$ the most junior. Any new class $j$ debt issued at date 1 ranks pari passu with existing debt of that class - in particular, it is junior to debt of classes $k<j$ and senior to debt of classes $k j$. Equity is junior to all debt in two senses: (i) it is entitled to a return only if all debt-holders have been fully paid; (ii) the 
firm always has the freedom to create an $(n+1)$ th class of debt of any size at date 1, which is junior to all existing debt but senior to equity. Finally, without loss of generality, we suppose that no additional equity can be issued at date 1.15

This description of debt and equity seems to accord with common usage (with the exception of our assumption that no new equity can be issued .. we return to this shortly) and, moreover, securities with these characteristics are observed in practice (see Brealey and Myers (1988)). Note that the above description allows for the possibility of "dilution" of debt in two ways.

For a given total date 2 payment $P$, the firm can give class $j$ debt-holders a lower share of $P$ either by issuing more debt of that class at date 1 (if $\Delta d_{j}$ $>0$ ) or by issuing more debt of a senior class (if $\Delta d_{k}>0$ for some $k<j$ ). In both cases more security-holders, senior to or of equal rank with class $\mathrm{j}$, have a claim to $P$ and so there will be less for class $j$ debt-holders. 16 Note that equity is infinitely dilutable given our assumption that the firm can issue unlimited amounts of class $(n+1)$ debt which is senior to it. It is for this reason that we assume that no new equity issues are allowed: such issues dilute existing equity, but in the present context they will have no effect since potential dilution is already infinite.

Let us now consider the relation between the above standard debt and equity package and the function $\mathrm{N}$ discussed before. Suppose it is known at date 1 that the firm's date 2 pay-out will be $P$. To calculate the maximum part of $P$ which can be earmarked for new security-holders, suppose the firm dilutes existing debt and equity as much as possible, i.e. at date 1 it takes on additional indebtedness of $\Delta d_{j}$ for each $j$ and creates an $(n+1)$ th class of debt to receive all remaining profit at the expense of equity (so $\left.\Delta d_{n+1}-\infty\right)$. Define $\hat{j}$ to be the most junior class that will receive a positive part of $P$, where $\mathrm{j}$ satisfies

$$
\left(d_{1}+\Delta d_{1}\right)+\ldots+\left(d_{j-1}^{\wedge}+\Delta d_{j-1}\right)<p \leq\left(d_{1}+\Delta d_{1}\right)+\ldots+\left(d_{j}+\Delta d_{j}^{\wedge}\right) .
$$

(That is, classes $1, \ldots, \dot{j}-1$ are fully paid, class $\dot{j}$ is only partially paid, and classes $\hat{j}+1, \ldots, n+1$ receive nothing.) Then the portion of $P$ accruing to new claimants at date 1 , represented by $N(P)$, equals 


$$
\begin{aligned}
& N(P)-\Delta d_{1}+\ldots+\Delta d_{j-1}^{\hat{j}}+ \\
& \left(\frac{\Delta d_{j}^{\hat{j}}}{d_{\hat{j}}+\Delta d_{\hat{j}}}\right)\left(P-\left(d_{1}+\Delta d_{1}+\ldots+d_{j-1}+\Delta d_{j-1}\right)\right)
\end{aligned}
$$

since new and old class $\hat{j}$ debt-holders are treated on a pro-rata basis. Initial date 0 claimants receive the residual $\mathrm{P}-\mathrm{N}(\mathrm{P})$.

Figure 2 illustrates $N(P)$. For $0 \leq P \leq d_{1}+\Delta d_{1}-P_{1}, \hat{j}-1$ (only the most senior class of creditors receive any payment) and the slope of $N(P)-$ $\Delta d_{1} /\left(d_{1}+\Delta d_{1}\right)$ (every extra dollar is divided in the proportions $\Delta d_{1}: d_{1}$ between new and old class 1 creditors). For $d_{1}+\Delta d_{1} \leq P \leq d_{1}+\Delta d_{1}+d_{2}+\Delta d_{2}-$ $P_{2}, \hat{j}-2$ and the slope of $N(P)-\Delta d_{2} /\left(d_{2}+\Delta d_{2}\right)$ (class 1 creditors are fully paid and every extra dollar is divided in the proportions $\Delta d_{2}$ : $d_{2}$ between new and old class 2 creditors). And so on ...

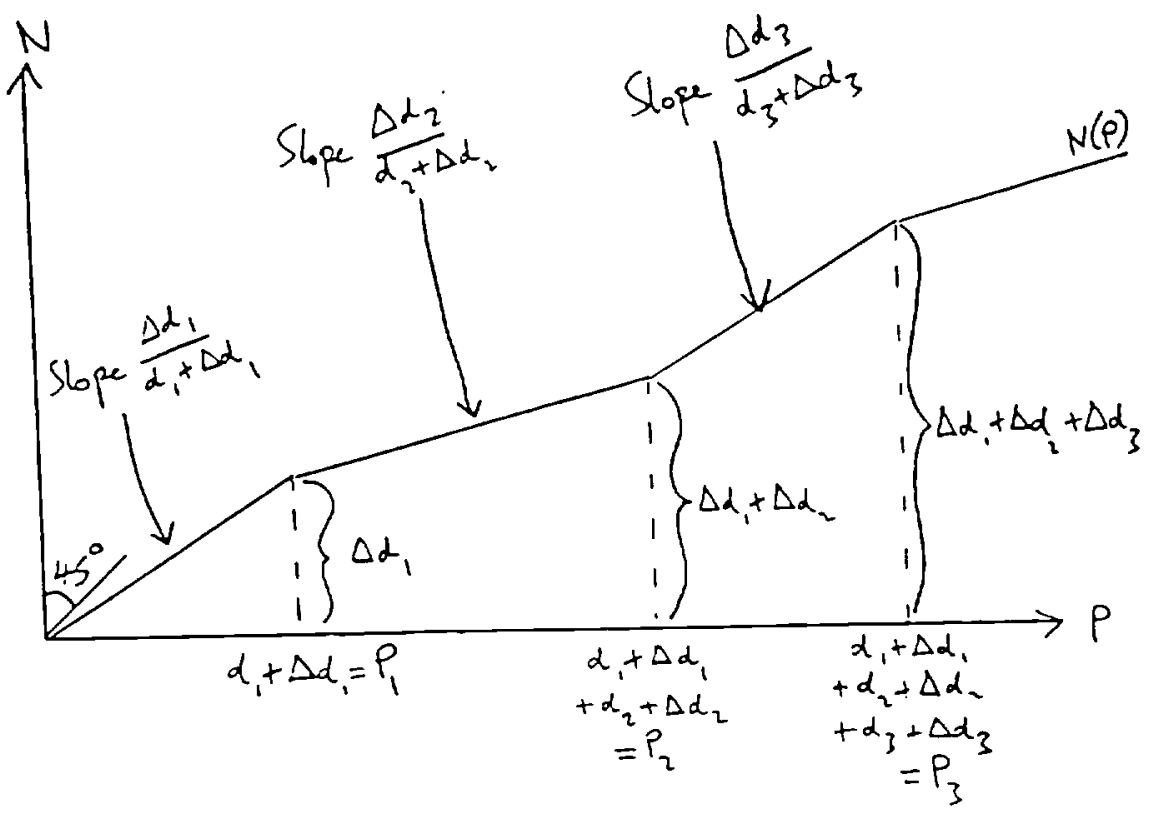

Figure 2 
We have seen how a standard debt/equity package yield a particular function $\mathrm{N}$ satisfying (2.2)-(2.3). It is also clear from Figure 2 that the converse holds: given any function $N$ satisfying (2.2)-(2.3), we can find a standard debt/equity package that implements it. Simply solve

$$
\begin{aligned}
& d_{1}+\Delta d_{1}=P_{1}, \\
& \Delta d_{1}-N\left(P_{1}\right),
\end{aligned}
$$

$$
\begin{gathered}
d_{1}+\Delta d_{1}+d_{2}+\Delta d_{2}-P_{2}, \\
\Delta d_{1}+\Delta d_{2}-N\left(P_{2}\right),
\end{gathered}
$$

and so on, where $P$ takes on the values $P_{1}<P_{2}<\ldots<P_{n}$. [The solution of (2.5) is $\Delta d_{1}-N\left(P_{1}\right), d_{1}-P_{1}-N\left(P_{1}\right), \Delta d_{2}-N\left(P_{2}\right)-N\left(P_{1}\right), d_{2}-P_{2}-N\left(P_{2}\right)$. $\left(P_{1}-N\left(P_{1}\right)\right\}, \ldots$. Note that $d_{j}, \Delta d_{j} \geq 0$ by $\left.(2.2)-(2.3).\right\}$

This procedure relies strongly on the finiteness of the random variable $P$. Note, however, that if $P$ is continuous, it is possible to approximate $N$ as closely as desired by choosing a random variable with finite support which approximates $P$.

Three simple examples of financial structure illustrate the foregoing discussion and act as useful reference points in our analysis of optimal financial structure in the next section.

(1) A pure equity firm (i.e. $d_{j}=\Delta d_{j}-0$ for all $j$ ).

$$
\begin{array}{r}
\text { Here } \hat{\jmath}-n+1, \Delta d_{n+1}-\infty \text { and so } \\
N(P)-P .
\end{array}
$$

In words, since equity can be infinitely diluted, all of $P$ can in principle be earmarked for new investors. 
(2) A firm with a single class of debt that cannot be diluted ( $n-1, d_{1}>0$, $\left.\Delta d_{1}-0\right)$.

$$
\begin{aligned}
& \text { Here for } P \leq d_{1}, \hat{j}-1 \text {, while for } P>d_{1}, \hat{j}-2 \text {. Thus }(2.4) \text { Implies } \\
& N(P)-\operatorname{Max}\left(P-d_{1}, 0\right),
\end{aligned}
$$

as in Figure $3 a$.

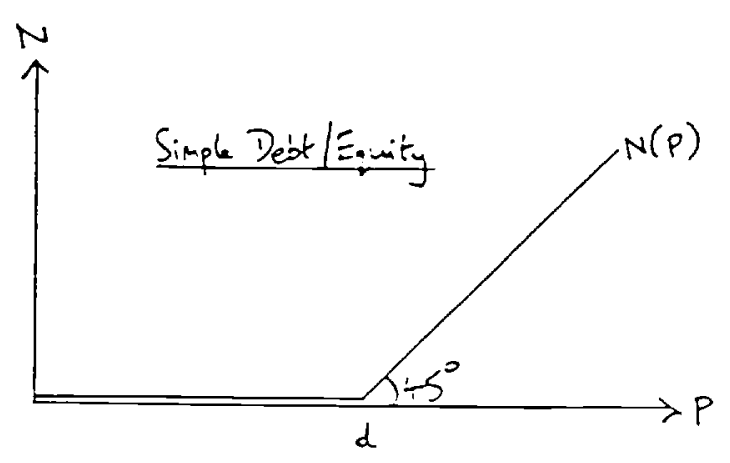

Figure $3 a$

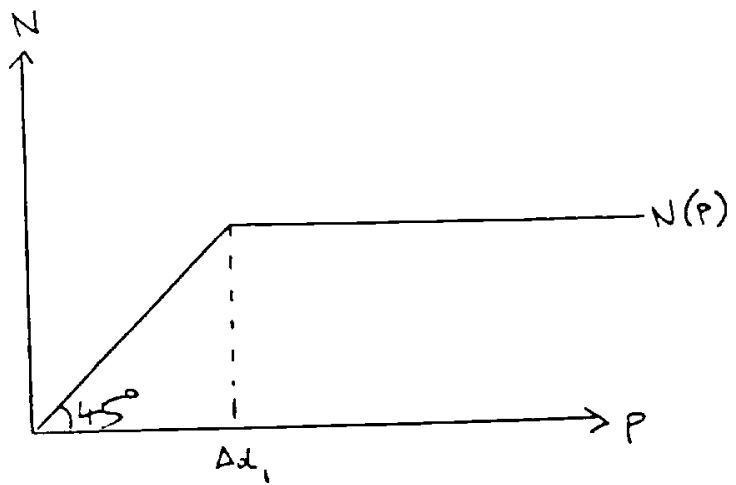

Figure 3b

That is, for $P \leq d_{1}$, all of $P$ must be given to senior debt-holders and there is none for new investors. On the other hand, for $P>d_{1}$, the firm can issue junior debt and give $P-d_{1}$ to new investors. We term this kind of security 
structure simple debt/equity.

(3) A firm with two classes of debt: a negligible amount of senior debt, with an option to borrow a finite amount of additional debt of the same seniority at date $1\left(d_{1} \cong 0, \Delta d_{1}>0\right)$; and a large amount of a second class of debt with no option to borrow any more $\left(d_{2}-\infty, \Delta d_{2}-0\right)$.

$$
\begin{gathered}
\text { Here for } P \leq \Delta d_{1}, \hat{j}-1 \text {, while for } P>\Delta d_{1}, \hat{j}-2 \text {. Thus, by }(2.4), \\
N(P)-\operatorname{Min}\left(P, \Delta d_{1}\right),
\end{gathered}
$$

as in Figure 3b.

In words, for $P \leq \Delta d_{1}$, all of $P$ can be earmarked for new holders of senior debt, but for $P \geq \Delta d_{1}$, all of the residual $P-\Delta d_{1}$ must be given to existing junior debt holders. 


\section{Optimal Security structures}

An optimal security structure, which solves (2.1) subject to (2.2)-(2.3), balances the following two competing objectives. On the one hand, if $N(P)$ is close to $P$, the manager will have a lot of scope for raising funds at $t-1$, and hence may make unprofitable investments. On the other hand, if $N(P)$ is close to zero, the manager will have little scope for raising funds and hence may miss profitable investments.

It is clear from (2.1) that a first-best security structure would ensure that $\mathrm{N}\left(\mathrm{r}+\mathrm{y}_{2}\right) \geq 1-\mathrm{y}_{1}$ if $\mathrm{r}>1$, and $\mathrm{N}\left(\mathrm{r}+\mathrm{y}_{2}\right)<1-\mathrm{y}_{1}$ if $\mathrm{r}<1$. Unfortunately, this is generally infeasible. However, if it were known that all potential investments were profitable, there would be no difficulty in obtaining the first-best.

\section{Proposition 1}

If $r$ always exceeds 1 , then the first-best can be obtained by issuing no debt at date 0 (a pure equity firm: $d_{j}=\Delta d_{j}=0$ for all $j$ ).

\section{Since there is no danger of the manager making an unprofitable} investment, it is best to give him the flexibility to raise as much money as he can at date 1 , by having no debt (i.e. setting $N(P)=P$ ) Notice that $\mathrm{N}\left(\mathrm{r}+\mathrm{y}_{2}\right)-\mathrm{r}+\mathrm{y}_{2} \geq \mathrm{r} \geq \mathrm{i} \geq 1-\mathrm{y}_{1}$, so the investment will always go ahead, as required in the first-best.

The opposite extreme, where no investment is ever profitable, is almost as simple.

\section{Proposition 2}

If $i$ always exceeds $r$, then at date 0 it is optimal to issue a large amount of nondilutable debt $\left(d_{1}-\infty, \Delta d_{1}-0\right)$. 
The effect of a large amount of nondilutable debt (i.e. setting $N(P)-$ $0)$ is to ensure that the manager is never able to raise further funds at $t-1$. However, this does not mean that he never invests. For if $y_{1}$ exceeds $i$ he will have enough cash to make the unprofitable investment anyway; in this event, investment cannot be deterred no matter what security structure is in place (and so in general the first-best is unobtainable). 17

Another simple case is where the total return from existing assets, $y_{1}+y_{2}$, is fixed.

Proposition 3

If $\mathrm{y}_{1}+\mathrm{y}_{2}$ is deterministic, then at date 0 it is optimal to issue an amount $\mathrm{y}_{1}+\mathrm{y}_{2}$ of a single class of nondilutable debt (a simple debt/equity structure: $d_{1}-y_{1}+y_{2}, \Delta d_{1}-0$ and $d_{j}-\Delta d_{j}-0$ for all $j>1$ ).

Proof If $y_{1} \geq 1$, then the investment will take place irrespective of $N($.$) .$ So the only event to consider is where the manager requires $i-y_{1}>0$ to make the investment. The proposition claims that $N(P)=\max \left(0, P-y_{1}-y_{2}\right)$ is optimal. Notice that with this $N($.$) , if the investment is to go ahead the$ manager can raise at most $\max \left(0, r+y_{2}-y_{1}-y_{2}\right)-\max \left(0, r-y_{1}\right\}$. The investment will then take place iff $\max \left(0, r-y_{1}\right) \geq 1-y_{1}$; i.e. iff $r \geq i$. Hence this must be an optimal $N($.$) : the manager's private incentives coincide with the$ social incentives when $i>y_{1}$.

Q.E.D.

The intuition behind Proposition 3 reveals something about how the general model works. The difficulty faced by the original security holders at date 0 is that they cannot disentangle the uncertain returns from existing assets $\left(y_{1}+y_{2}\right)$ from the uncertain returns from new investment $(x-1)$.

Proposition 3 tells us that this difficulty disappears if the total return 
$y_{1}+y_{2}$ from existing assets is fixed. One can mortgage this return by issuing undilutable senior debt $\mathrm{d}_{1}-\mathrm{y}_{1}+\mathrm{y}_{2}$ at date 0 ; and because the manager can only issue securities junior to $d_{1}$, he cannot invest at date 1 without first convincing the market that it is profitable. (The exception are those states of nature in which $y_{1} \geq 1$, where the manager has sufficient cash at date 1 to pay for the investment -. profitable or otherwise .. without returning to the market.) 18

The optimal security structure in Proposition 3 corresponds to what we called simple debt/equity in Section 2: a single class of debt, $d_{1}-y_{1}+y_{2}$, which cannot be diluted. 19 In Propositions 4, 6 and 7 below we will see that there are many other distributions $F\left(y_{1}, y_{2}, i, r\right)$ for which a simple debt/equity structure is optimal.

It is not always the case that an optimal security structure takes such a simple form.

\section{Example 1}

Suppose $y_{1}=0$ and $r=g\left(y_{2}\right)$, where $g($.$) is a continuous, strictly$ increasing, deterministic function. Then one can obtain first-best by putting $N(P)-N$, the (unique) solution to

$$
N+g^{-1}(N)-P
$$

(It is straightforward to confirm that (2.2) and (2.3) hold.) For a given $r$ (and hence $y_{2}=g^{-1}(r)$ ), the manager can raise up to $N\left(r+y_{2}\right)$ to finance the investment. But by construction, $\mathrm{N}\left(\mathrm{r}+\mathrm{y}_{2}\right)-\mathrm{r}$. Moreover, since $\mathrm{y}_{1}=0$, the manager needs to raise the full cost $i$ to make the investment - which means he will be in a position to invest iff $r \geq i$ (i.e. the first-best is implemented).

A special case of this example is where $\mathrm{g}($.$) is linear, say r-\theta \mathrm{y}_{2}$, where $\theta>0$. In this case a linear sharing rule between old and new investors is optimal: $N(P)-\theta P /(1+\theta)$. One could implement this simply by issuing a 
large single class of debt $d_{1}$ at date 0 , with a covenant to the effect that a further amount $\Delta d_{1}-\theta d_{1}$ of the same class can be subsequently issued at date 1 .

To make progress in characterising an optimal security structure for the ' general case, it is helpful to make use of our earlier assumption that $\left(y_{1}, y_{2}, i, r\right)$ take only a finite number of values. In particular, we shall assume that they take only integer values. 20

As can be seen from program (2.1), the only thing that matters about a security structure is whether or not $N\left(r+y_{2}\right) \geq i-y_{1}$ for each vector of realisations $\left(y_{1}, y_{2}, i, r\right)$. Given that $y_{1}, y_{2}, i, r$ take only integer values, it follows that w.1.0.g. we can restrict $N($.$) to be an integer too. 21$ In effect, we choose

$$
n_{P}-N(P)-N(P-1)
$$

to be elther 0 or 1 (the two constraints on $N($.$) imply that n_{p}$ cannot take values other than 0 or 1 ), where, since $N(0)=0$,

$$
N(P)-\sum_{P^{0}=1}^{P} n_{p^{0}} .
$$

Take some $\mathrm{P}$ for which $\mathrm{n}_{\mathrm{P}}-1$. Consider the ramifications of lowering $n_{p}$ from 1 to 0 - in effect lowering $N(\hat{P})$ by 1 for all $\hat{P} \geq P$. This will stop the manager from making certain investments which he hitherto was able to make. In particular, the manager will cease to invest in any realisation $\left(y_{1}, y_{2}, i, r\right)$ such that

$$
\begin{aligned}
& N\left(r+y_{2}\right)-i-y_{1} \\
& \text { and } r+y_{2} \geq p \text {, }
\end{aligned}
$$

where $\mathrm{N}($.$) is the old security structure (i.e. prior to the reduction in n_{P}$ ). To see this, set $r+y_{2}=\hat{P}$. We learn from $N(\hat{P})-i-y_{1}$ that in this state the 
manager was only just able to make the investment 1 . But since $\hat{P} \geq P$, we know that the effect of changing $n_{P}$ from 1 to 0 is to lower $N(P)$ by 1 ; and so after the change the investment $i$ is infeasible.

of course some of the lost investments may have been profitable, others unprofitable. The net loss to the date 0 investors must be nonnegative at an optimum:

$$
\begin{aligned}
& \quad \int(r-i) d F\left(y_{1}, y_{2}, i, r\right) \geq 0 \text { if } n_{p}-1 . \\
& N\left(r+y_{2}\right)-i-y_{1} \\
& \quad r+y_{2} \geq P
\end{aligned}
$$

A similar line of reasoning applies if $n_{p}-0$. Specifically, at an optimum the date 0 investors cannot benefit from changing $n_{p}$ from 0 to 1 (thereby enabling the manager to raise additional funds in certain states of nature) :

$$
\begin{aligned}
& \int(r-i) d F\left(y_{1}, y_{2}, i, r\right) \leq 0 \text { if } n_{P}-0 . .^{22} \\
& \underset{r+N\left(r+y_{2}\right)-i-y_{1}}{r+y_{2} \geq P}
\end{aligned}
$$

The two "first-order" conditions (FOCl) and (FOC2) can be usefully combined. Consider a $P$ for which $n_{P}-1$ and $n_{P+1}=0$. The net loss to the date 0 investors from switching to $n_{P}-0$ and $n_{P+1}-1$ must be nonnegative at an optimum:

$$
\begin{aligned}
& \int(r-i) d F\left(y_{1}, y_{2}, i, r\right) \geq 0 . \\
& N\left(r+y_{2}\right)-i-y_{1} \\
& r+y_{2}-P
\end{aligned}
$$

$$
\text { or equivalently: } \quad E\left[r-i \mid r+y_{2}-P \& i-y_{1}-N(P)\right] \geq 0
$$


where we adopt the convention

$$
E\left[r-i \mid r+y_{2}-P \& i-y_{1}-N(P)\right]-0 \text { if } \quad \operatorname{Prob}\left\{r+y_{2}-P \& i-y_{1}-N(P)\right\}=0 \text {. }
$$

We can learn quite a lot about the nature of an optimal security structure from the behaviour of the conditional expectations:

$$
K(P, N)=E\left[r-i \mid r+y_{2}-P \& i-y_{1}-N\right]
$$

In particular, the following condition and lemma will be important:

Condition $K$ For any $P, N$ such that $P \geq N$ :

$$
K(P, N)>0 \quad \rightarrow \quad K(\hat{P}, \hat{N}) \geq 0 \text { for any } \hat{P}-P \geq \hat{N}-N \geq 0 \text {. }
$$

Lemma If Condition $K$ holds, then a simple debt/equity security structure is optimal.

Proof See Appendix.

The intuition behind the Lemma is straightforward. $K(P, N(P))$ is the expected value of a marginal date 1 investment given a total date 2 payout of $P$. Condition $K$ implies that there is a cutoff value of $P$, say $P *$, such that the expected value of a marginal date 1 investment is negative [resp. positive] if $P<P *$ [resp. $\left.P>P^{*}\right]^{23}$ other things equal, then, one would like to lower $N(P)$ for $P<P *$, and raise $N(P)$ for $P>P *$. But we have to contend 
with the constraints (2.2) and (2.3). It should be clear from Figure $3 a$ that a simple debt/equity security structure does a good job of balancing these goals.

Propositions 4,6 and 7 give different sets of sufficient conditions on the joint distribution $F\left(y_{1}, y_{2}, i, r\right)$ for Condition $k$ to be satisfied.

\section{Proposition 4}

If (4a) i is deterministic,

$y_{1}$ is independent of $y_{2}$ and $r$,

(4b) $E\left(r \mid r+y_{2}-P\right)$ is increasing in $P$,

then at date 0 a simple debt/equity security structure is optimal. 24

Proof (4a) implies that $K(P, N)$ is independent of $N$. And together with (4b), it implies that $K(P, N)$ is increasing in $P$. Hence Condition $K$ is satisfied. Now apply the Lemma.

Q.E.D.

The intuition behind Proposition 4 is that, when $i$ is fixed, new investment should not occur for low values of $r+y_{2}$ - since this signifies low $r$, on average; whereas the investment should go ahead for high values of $\mathrm{r}+\mathrm{y}_{2}$. A simple debt/equity security structure implements this quite well: for low values of $\mathrm{r}+\mathrm{y}_{2}$ the manager is unable to raise funds at $\mathrm{t}=1$ and is therefore less likely to be in a position to invest; conversely for high values of ${\mathrm{r}+\mathrm{y}_{2}}_{2} \cdot 25$

Before we move on to the other results relating to simple debt/equity, it is worth looking at the opposite case to Proposition 4. 


\section{Proposition 5}

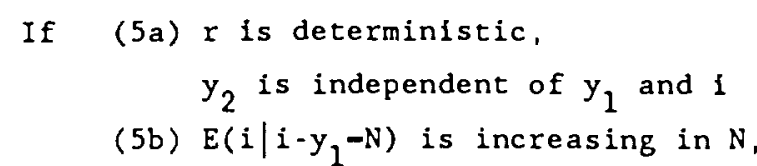

then it is optimal at date 0 to issue two classes of debt: a negligible amount of senior debt, with an option to borrow a finite amount of additional debt of the same senfority at date $1\left(d_{1} \cong 0, \Delta d_{1}>0\right)$; and a large amount of a second class of debt with no option to borrow any more $\left(d_{2}-\infty, \Delta d_{2}-0\right)$.

Recall that we considered this form of security structure in the final example in Section 2; see Figure $3 b$ and surrounding discussion. In a sense it is the obverse of simple debt/equity: the manager can raise the first $\Delta d_{1}$ of any $P$, but no more $\left(N(P)-\min \left(P, \Delta d_{1}\right)\right.$.

The intuition behind Propositions 5 is that, given a fixed $r$, low/high values of $i$ represent good/bad investment opportunities and should be encouraged/discouraged. To this end, the manager is enabled to borrow up to a fixed amount of money $\Delta d_{1}$ but no more. 26

The next two propositions concern the case where all four variables $\mathrm{y}_{1}, \mathrm{y}_{2}, 1, \mathrm{r}$ are independently distributed, and Condition $\mathrm{k}$ applies. ${ }^{27}$ The propositions are likely to generalize to the case of positive correlation between $y_{2}$ and $r$, however, since this is helpful to Condition $k$. This is useful to know, since in practice one might expect there to be some common shock to the returns from existing assets and the return from new investment (c.f. the numerical example in the Introduction). 
Proposition 6

Suppose $y_{1}, y_{2}, i$ and $r$ are independent and uniformly distributed on the discrete consecutive integer supports $\left(\underline{y}_{1}, \ldots, \bar{y}_{1}\right),\left(y_{2}, \ldots, \bar{y}_{2}\right), 1$. $\ldots, \bar{i})$ and $(\underline{r}, \ldots, \bar{r})$ respectively. Then if

(6a)

$$
\bar{r}-\underline{r} \geq \bar{y}_{2}-y_{2}
$$

$$
\text { and } \overline{\mathrm{I}}-\underline{1} \leq \bar{y}_{1}-\mathrm{y}_{1}
$$

a simple debt/equity security structure is optimal at date 0 .

Proof See Appendix.

We can also make progress in the case where the four variables $\left(y_{1}, y_{2}, i, r\right)$ are approximately normally distributed. The advantage of the normal distribution is that it yields a simple expressions for $K(P, N)$. Specifically, if for the moment we ignore nonnegativity and finiteness, and assume that $\left(\mathrm{y}_{1}, \mathrm{y}_{2}, \mathrm{i}, \mathrm{r}\right)$ are independently normally distributed with means $\left(\mu_{1}, \mu_{2}, \mu_{i}, \mu_{r}\right)$ and variances $\left(\sigma_{1}^{2}, \sigma_{2}^{2}, \sigma_{i}^{2}, \sigma_{r}^{2}\right)$ respectively, then from standard distribution theory it follows that

$$
K(P, N)=\mu_{r}+\left(\frac{\sigma_{r}^{2}}{\sigma_{r}^{2}+\sigma_{2}^{2}}\right)\left(P-\mu_{r}-\mu_{2}\right]-\mu_{i}-\left(\frac{\sigma_{i}^{2}}{\sigma_{i}^{2}+\sigma_{1}^{2}}\right)\left[N-\mu_{i}+\mu_{1}\right] .
$$

Notice that Condition $K$ is satisfied if $\frac{\sigma_{r}^{2}}{\sigma_{r}^{2}+\sigma_{2}^{2}} \geq \frac{\sigma_{1}^{2}}{\sigma_{i}^{2}+\sigma_{1}^{2}}$; and we can then appeal to the Lemma to show that a simple debt/equity security structure is optimal. This is the method of proving: 


\section{Proposition 7}

Consider a set of four distributions $F_{1}\left(y_{1}\right), F_{2}\left(y_{2}\right), F_{1}(i)$ and $F_{r}(r)$ which are each constructed by truncating normal distributions $N\left(\mu, \sigma^{2}\right)$ to the left of zero (and scaling so as to integrate to 1 over the remaining support, $\left.R_{+}\right)$- where $\mu-\mu_{1}, \mu_{2}, \mu_{i}, \mu_{r}$ and $\sigma-\sigma_{1}^{2}, \sigma_{2}^{2}, \sigma_{i}^{2}, \sigma_{r}^{2}$ respectively. Now take a sequence of similar distributions

$$
\left(F_{1}{ }^{m}\left(y_{1}\right), F_{2}{ }^{m}\left(y_{2}\right), F_{i}{ }^{m}(i), F_{r}{ }^{m}(r) \mid m=0,1,2,3, \ldots\right)
$$

which are constructed in the same manner, except that a constant $m$ is added to the $\mu^{\prime} s$ (prior to the truncation).

$$
\text { Suppose } \frac{\sigma_{r}^{2}}{\sigma_{r}^{2}+\sigma_{2}^{2}}>\frac{\sigma_{i}^{2}}{\sigma_{i}^{2}+\sigma_{1}^{2}} \text {. }
$$

Then there exists an $M$ such that for $m \geq M$, if $y_{1}, y_{2}$, $i$ and $r$ are independent and have distributions $F_{1}{ }^{m}\left(y_{1}\right), F_{2}{ }^{m}\left(y_{2}\right), F_{i}{ }^{m}(i), F_{r}{ }^{m}(r)$, a simple debt/equity security structure is optimal at date $0 .{ }^{28}$

Propositions 4, 6 and 7 can be interpreted as saying that if the riskiness of the return from new investment (relative to that of the return from existing assets at date 2) is higher than the riskiness of the size of the new investment (relative to the return from existing assets at date 1 ), then a simple debt/equity security structure is optimal at date 0 . 
We turn now to some comparative statics analysis. Specifically, we ask: assuming that a simple debt/equity security structure is optimal at date 0 . how does the size of the optimal debt level change with the joint distribution $\mathrm{F}\left(\mathrm{y}_{1}, \mathrm{y}_{2}, \mathrm{I}, \mathrm{r}\right)$ ? Let the optimal debt level be $d$. From program (2.1) we know that this will be chosen to

$$
\text { maximize } \quad \int(r-i) d F\left(y_{1}, y_{2}, i, r\right) .
$$

If we treat $F$ as continuous for the moment, we can express the first-order condition for an interior optimum as

$$
E\left[r-i \mid r-i+y_{1}+y_{2}-d \& i \geq y_{1}\right]=0
$$

or, equivalently,

$$
E\left[r-i \mid r-i+y_{1}+y_{2}=d \& r+y_{2} \geq d\right]=0.29
$$

The following two, rather natural, conditions enable us to determine how the optimum debt level changes with the means of $y_{1}, y_{2}, i$ and $r$. 
Condition C

$$
\begin{aligned}
& 0 \leq \frac{\partial}{\partial d} E\left[r-i \mid r-i+y_{1}+y_{2}-d \& i \geq y_{1}\right] \leq 1 \quad \text { for all } d ; \\
& 0 \leq \frac{\partial}{\partial d} E\left[r-i \mid r-1+y_{1}+y_{2}-d \& r+y_{2} \geq \hat{d}\right] \leq 1 \text { for all } d, \hat{d} .
\end{aligned}
$$

Although nefther half of Condition $C$ is automatically satisfied, each is nonetheless quite intuitive: given two random variables $X-r-i$ and $Y-y_{1}+y_{2}$, the conditional expectation of $X$ given $X+Y-d$ will typically rise $\cdots$ but by less than a dollar - - for every dollar increase in d. (And by assumption this simple idea is not complicated by the presence of the additional conditioning inequalities $i \geq y_{1}$ and $r+y_{2} \geq \hat{d}$ respectively -. which, notice, are independent of d.)

\section{Proposition 8}

Suppose that a simple debt/equity security structure is optimal at date 0 . Then if Condition $C$ is satisfied, the optimal debt level $d$ will rise as
(a) a positive constant is added to $y_{1}, y_{2}$ or $i$
(b) a positive constant is subtracted from $r$

(i.e. as the means of $y_{1}, y_{2}$ or $i$ rise, or as the mean of $r$ falls - leaving variances unaffected). Moreover, a dollar shift in $y_{2}$ will lead to a dollar increase in $d$.

Proof See Appendix. 
The intuition behind Proposition 8 is stralghtforward. An increase in the mean of 1 , or a decrease in the mean of $r$, implies that investments are less likely to be profitable, and there is therefore a need to constrain the manager with higher debt. As the mean of $y_{1}$ rises, the manager has more cash with which to invest at date 1 , and so at the margin his ability to borrow should be further constrained: the debt level should rise. Finally, if a dollar is added to every realisation of $y_{2}$, then at date 2 a total payout of $\$ \mathrm{P}+1$ has the same significance (in terms of revealing information about $r$ ) as a payment of $\$ P$ would have had prior to the change; hence the optimal $N($. schedule shifts to the right by a dollar - . implying that the optimal debt level rises by a dollar.

To make these points more concretely, and to understand certain other effects, we now look at two examples. For simplicity we shall suppose that $y_{1}$ and $i$ are certain, with $i>y_{1}$ (otherwise the manager could always invest at date 1). From Footnote 24, we know that simple debt/equity is an optimal security structure. Let $d$ be the optimal debt level. We examine the comparative statics properties of $d$ not just with respect to the means (Proposition 8), but also with respect to the variances of $y_{2}$ and $r: \sigma_{2}^{2}$ and $\sigma_{r}^{2}$ respectively. We then suggest reasons why these variance effects are robust.

Example 2

Suppose $y_{1}$ and $i$ are deterministic, with $i>y_{1}$; and $y_{2}$, $r$ are independent and (approximately) normally distributed with means $\mu_{2}{ }^{\prime} \mu_{r}$ and variances $\sigma_{2}^{2}, \sigma_{r}^{2}$. (C.f. Proposition 7.) Then by standard distribution theory the LHS of (3.2) is simply

$$
\mu_{Y}-i+\left(\frac{\sigma_{r}^{2}}{\sigma_{r}^{2}+\sigma_{2}^{2}}\right)\left[d-y_{1}-\mu_{2}-\mu_{Y}+i\right] .
$$


and hence the optimal debt level $d$ is

$$
\mathrm{d}-\mathrm{y}_{1}+\mu_{2}-\frac{\sigma_{2}^{2}}{\sigma_{\mathrm{r}}^{2}}\left[\mu_{\mathrm{r}}-1\right] .
$$

It follows that $d$ rises as $y_{1}, \mu_{2}$, $i$ rise and/or $\mu_{r}$ falls - - confirming Proposition 8. Also, notice that if new investment is on average profitable (i.e.. $\left.\mu_{r}>i\right)$, then d rises as $\sigma_{r}^{2}$ rises and/or $\sigma_{2}^{2}$ falls; and vice versa if new investment is on average unprofitable $\left(\mu_{r}<i\right)$. These variance results also hold for next example.

\section{Example 3}

Suppose $y_{1}$ and $i$ are deterministic; with $i>y_{1}$; and $y_{2}, r$ are independent and uniformly distributed on $\left[\mu_{2}-s_{2}, \mu_{2}+s_{2}\right],\left[\mu_{r}-s_{r}, \mu_{r}+s_{r}\right]$ respectively. (C.f. Proposition 6.) (30 $^{30}$

In order to reduce the number of cases under consideration, we assume that $s_{r}<s_{2}$; there are then only two cases to consider: (a) $\mu_{r}>i$ (new investment is on average profitable); and (b) $\mu_{r}<i$ (new investment is on average unprofitable). 31

Case (a) $\mu_{r}>i$ (new investment is on average profitable)

To avoid making the case uninteresting, assume that $\mu_{r}-s_{r}<i$ (otherwise the optimal d would be zero, by Proposition 1).

The optimal debt level $d$ is indicated in Figure 4 - where the support of $y_{1}+y_{2}$ is the horizontal of the rectangle, and the support of $r-i$ is the vertical. Notice that conditional on $(r-i)+\left(y_{1}+y_{2}\right)-d-i$.e. conditional on lying along the $135^{\circ}$ line intersecting the rectangular support - the expectation of $\mathrm{r}-\mathrm{i}$ is zero, as required by (3.2a). 32 


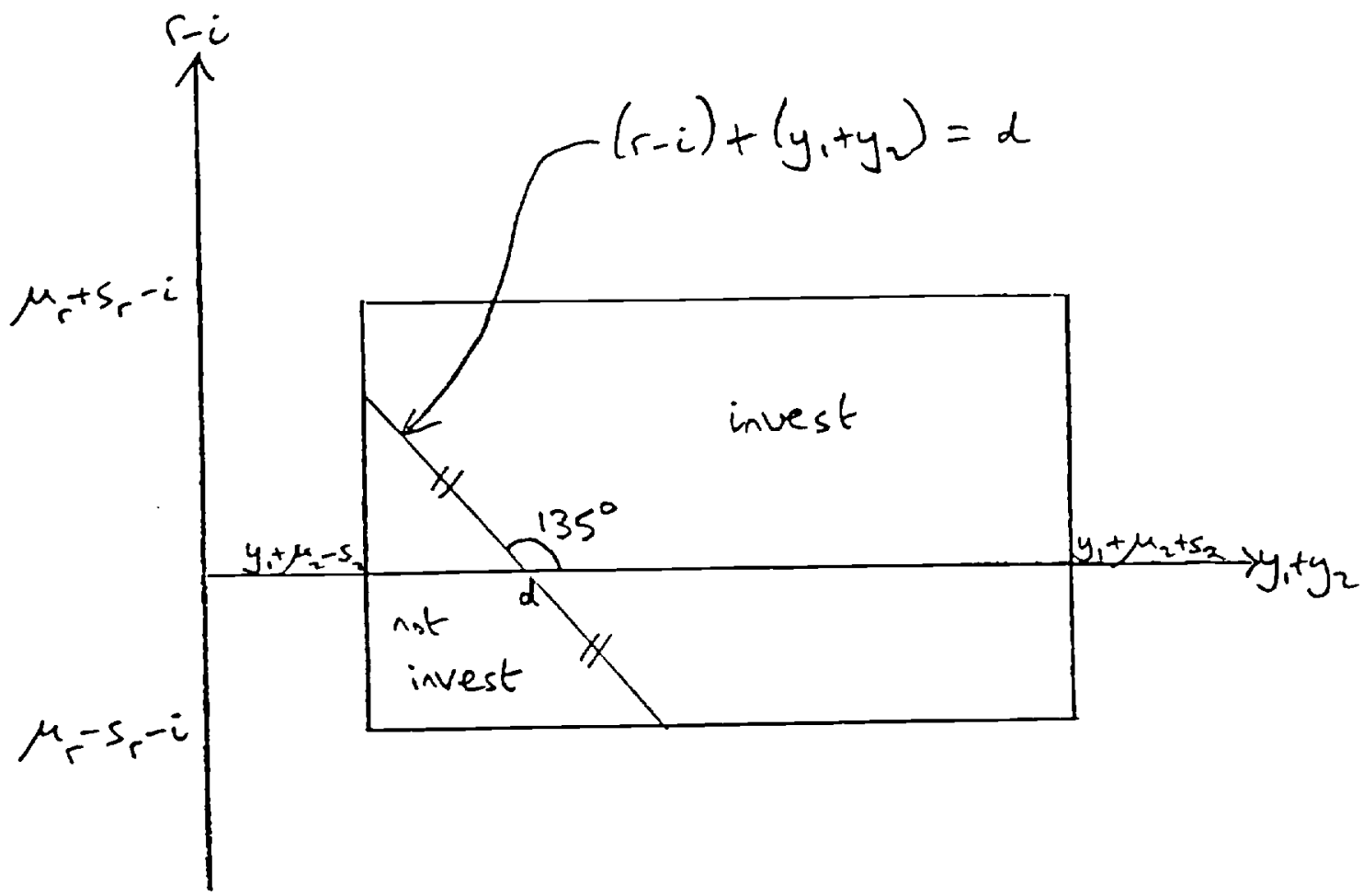

Figure 4: Example 3, Case (a): $\mu_{r}>i$

From the figure it is clear that the optimal debt level must satisfy

$$
\begin{array}{r}
d-\left(y_{1}+\mu_{2}-s_{2}\right)-\left(\mu_{r^{-}}-i\right) ; \\
\text { i.e. d }-y_{1}+\mu_{2}-s_{2}-\mu_{r}+s_{r}+i .
\end{array}
$$

It follows that $d$ rises as $y_{1}, \mu_{2}$, i rise and/or $\mu_{r}$ falls - confirming Proposition 8. Also, d rises as $s_{r}$ rises and/or $s_{2}$ falls - confirming the variance results of Example 2 . 
Case (b) $\mu_{r}<\mathbf{i}$ (new investment is on average unprofitable)

To avoid making the case uninteresting, assume that $\mu_{r}+s_{r}>i$ (otherwise the optimal d would be infinity, by proposition 2).

This is very similar to case (a), except that now the relevant diagram is as in Figure 5 .

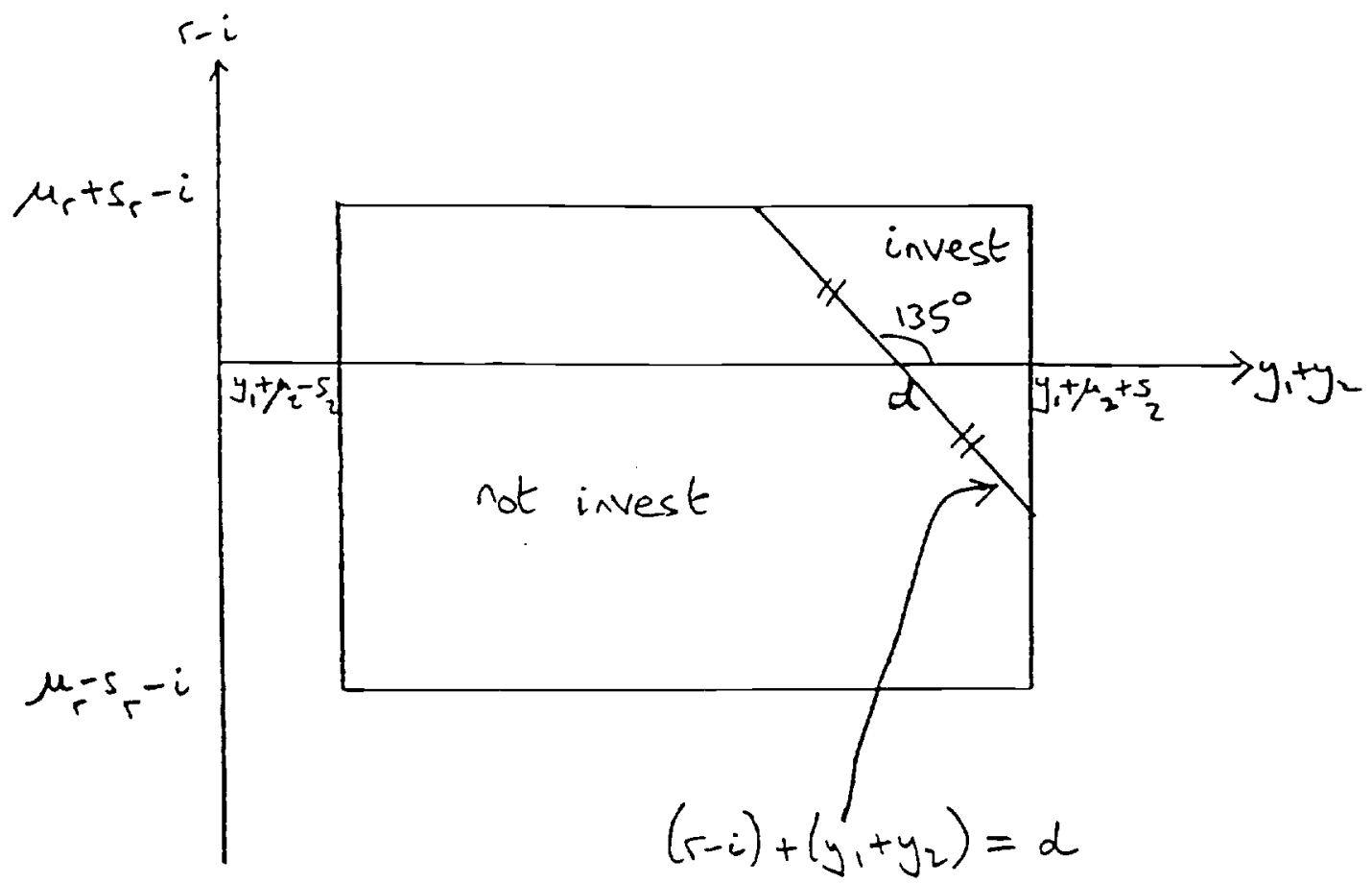

Figure 5: Example 3, Case (b): $\mu_{\mathrm{r}}<\mathrm{i}$

From the figure it is clear that the optimal debt level must satisfy 


$$
\begin{aligned}
& \text { d }-\left(y_{1}+\mu_{2}+s_{2}\right)-\left(\mu_{\mathrm{r}}+s_{\mathrm{r}}-\mathrm{i}\right) \\
& \text { i.e. } \quad \mathrm{d}-\mathrm{y}_{1}+\mu_{2}+s_{2}-\mu_{\mathrm{r}}-s_{\mathrm{r}}+i .
\end{aligned}
$$

It follows that $d$ rises as $y_{1}, \mu_{2}$, I rise and/or $\mu_{r}$ falls -. confirming Proposition 8 . Also, $d$ rises as $s$ falls and/or $s_{2}$ rises -- confirming the variance results from Example 2. ${ }^{33}$

To surmarize what we have learned so far from Examples 2 and 3:

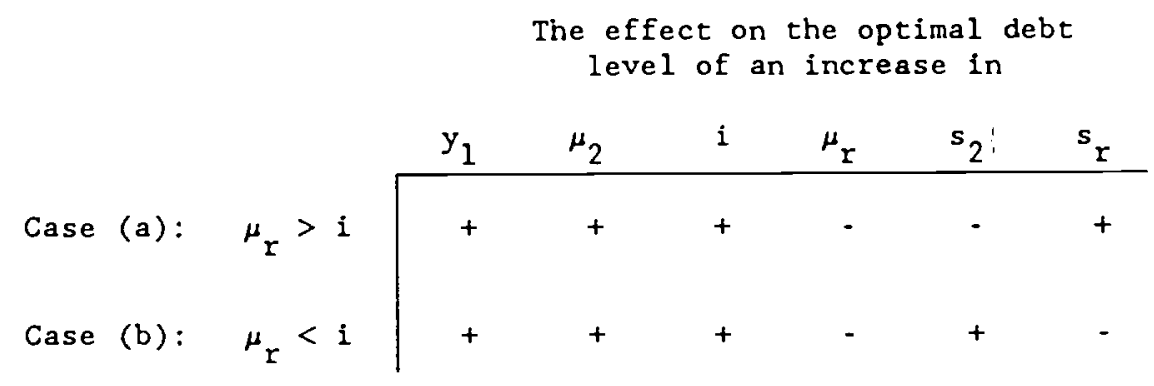

Table 1

We believe that the variance results of Examples 2 and 3 are fairly robust. To see this, consider the case where $\mu_{r}>1$ and $\sigma_{r}^{2}$ is just small enough that all new investments are profitable. Then it is optimal to set the debt level at or below $y_{1}+\underline{y}_{2}$, where $y_{2}$ is the minimum possible value of $y_{2}$; this ensures that all investments take place. Now raise $\sigma_{r}^{2}$ so that $r$ is occasionally just below $i$. At the margin, the debt should be raised to above $y_{1}+y_{2}$, to prevent the manager from making bad investments in at least the lowest $y_{2}$ states. That is, $d$ rises as $\sigma_{r}^{2}$ rises, as in Table 1 . In fact, the new optimal debt level will be just above $y_{1}+y_{2}$ (if it were much higher, then profitable investments would be missed in the low $y_{2}$ states). It follows that an increase in $\sigma_{2}^{2}$.. because it lowers $y_{2}$ - lowers the optimal debt level. That is, $d$ falls as $\sigma_{2}^{2}$ rises, as in Table 1 . 
There is another way of understanding this. As $\sigma_{2}^{2}$ rises relative to $\sigma_{r}^{2}$ there is less information about $r-i$ from the fact that $r-i+y_{1}+y_{2}-d$. In the limlt, the LHS of (3.2) becomes simply $\mu_{r}-1$, and there won't be an interior optimum. If $\mu_{r}>i$, it is best to give the manager maximum freedom to finance new investment; i.e. set d-o. Put simply, if the manger's ability to raise fresh capital at date 1 is almost entirely determined by the realized returns from existing assets, then there is little point in using a security structure to screen out the bad new investments. One may as well rely on prior (date 0) information - - 1.e. whether or not new investments are on average profitable.

It will be clear from the last argument why, if new investments are on average unprofitable, the comparative statics properties of the variances $\sigma_{2}^{2}$ and $\sigma_{r}^{2}$ are reversed.

The values of debt and equity

For the purposes of empirical testing, it is useful to know also how the value of debt - - and of equity, and of the debt/equity ratio - change with the underlying parameters. Example 3 provides a useful vehicle to study this question, since these values can be calculated explicitly. (Explicit formulae are not available for the normal case, Example 2.) In the Appendix we establish the following comparative statics properties: 


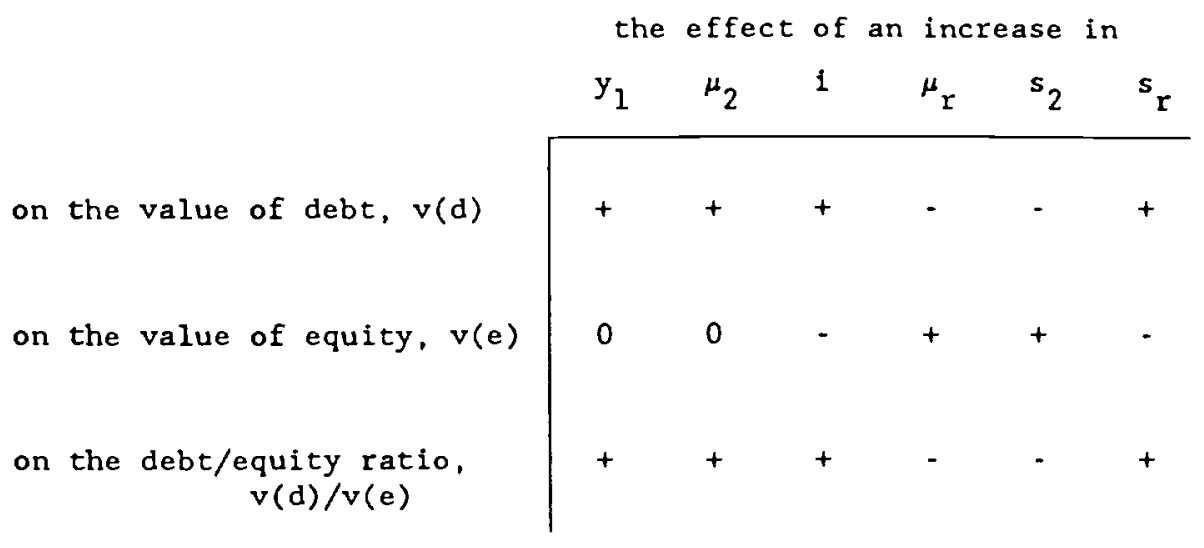

Table 2: Example 3, Case (a): $\mu_{\mathbf{r}}>\mathrm{i}$

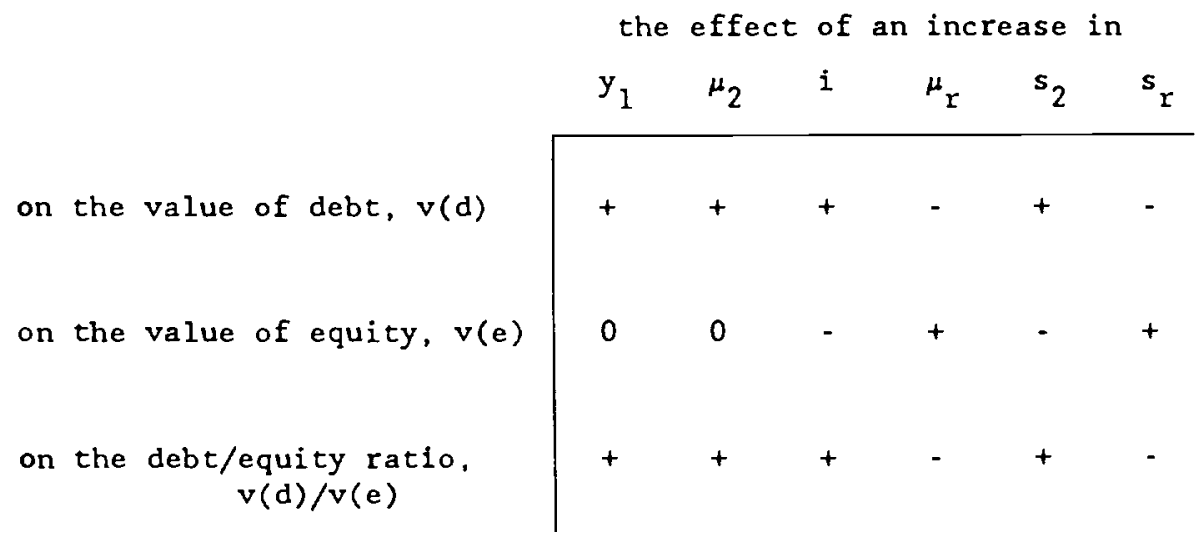

Table 3: Example 3, Case (b): $\mu_{x}<i$

Notice from Tables $1-3$ that the comparative statics properties of the value of debt mirror those of the level of debt. Also, the value of equity 
has the opposite comparative statics properties. Thus the debt/equity ratio has the same comparative statics properties as debt.

We should add a caveat. Even for this relatively simple example, the values of debt and equity reflect quite a subtle combination of effects. For this reason, the results in Tables 2 and 3 are probably less robust than those in Table 1. 


\section{Conclusions and Extensions}

Our theory has a number of empirical implications which seem worth investigating. First in those cases where simple debt and equity are optimal, we have derived a number of testable comparative statics properties. We have shown that (ceteris paribus): the higher is the average profitability of a firm's new investment project, the lower will be the level of debt; the higher is the average profitability of a firm's existing assets (assets in place), the higher will be the level of debt. In addition: an increase in the riskiness of new investment projects raises the optimal debt level if the average return on new projects is positive, but lowers it if the average return on new projects is negative; and an increase in the riskiness of assets in place lowers the optimal debt level if the average project return is positive but raises it if it is negative.

Some of these predictions are novel. For example, a theory which trades off the tax benefits of debt against the bankruptcy costs of debt would not distinguish between assets in place and new investments, and would predict a positive correlation between profitability and the debt level. In contrast, our theory explains the observed strong negative correlation between profitability and leverage (see Kester (1986) and Myers (1990)), as long as high profitability is associated with new projects. Another difference between the tax theory and our theory is that whereas the tax theory predicts that the debt level falls as a firm's return becomes riskier (since the probability of bankruptcy rises), our theory predicts that the (long-term) debt level rises if new projects become riskier and are on average profitable or if assets in place become riskier and new projects are on average unprofitable. Finally, our theory can explain why managers increase leverage in response to a hostile takeover (to bond themselves not to undertake future investment), and hence why most leverage-increasing transactions raise market value (of course, other theories can also explain this finding; see Myers (1990)).

Our theory also suggests a new way of thinking about the "flexibility" of a firm's financial position. Consider a firm which, for some reason, 
suddenly needs an injection of new capital just to keep going (an example would be where an uninsured factory burns down). The most that the firm can raise from the capital market to deal with this emergency can be regarded as a measure of the firm's flexibility or financial slack. In the case of a firm with simple debt-equity, this measure is given by the current value of equity, since the firm can always in extremis raise this sum by issuing a large enough amount of junior debt (or new equity). Our framework suggests that for the case of a firm which does not have simple debt-equity, a more appropriate measure of slack is EN(P) (where the expectation is taken with respect to $P$ ); this typically exceeds the value of equity since it includes the amount by which existing debt can be diluted (see (2.4)). Our analysis yields the rough prediction that optimal financial structure will be chosen so that $E N(P)$ will be greater - - to give the manager more flexibility to invest - the more desirable is new investment.

An important assumption that we have made is that a firm cannot renegotiate with its, claim-holders at date 1 when a new investment project becomes avallable. Note that, if renegotiation were costless, there would be no disadvantage in having high debt since if the new project had positive net present value the creditors would always be prepared to renegotiate their claims so as to allow the project to go ahead. Thus in a world of costless renegotiation, it would be optimal to have infinite (or very high) debt, in effect forcing the firm to return to the capital market - - or, to put it another way, to seek permission from its creditors - for every new investment.

Such an extreme outcome is unrealistic, and there are strong theoretical reasons why. Because investors are wealth-constrained and risk averse, a major corporation will typically be financed by a sizable number of relatively small investors, rather than a small number of very large ones. But this means that free-rider and hold-out problems are likely to make renegotiation extremely difficult, if not impossible. In particular, if the debt level is too high to allow a positive NPV project to take place, then while it is in the collective interest of creditors to forgive a portion of the debt, it is in any single creditor's interest to refuse to forgive his 
share since the chance that his decision will affect the outcome is very small. Thus in many cases one would expect the renegotiation process to break down and investment not to occur; moreover there is plenty of evidence - casual and otherwise - that this frequently happens in practice. 34

One possible way round the free-rider problem is to include a provision in the initial debt contract that the aggregate debt level can be reduced as long as a majority of creditors approve (i.e. the majority's wishes are binding on the minority). It turns out that such a provision is illegal in the U.S. ${ }^{35}$ However, even if it were legal, there are strong theoretical reasons for thinking that it would not solve the problem. For majority rule to work well, individual investors must keep abreast of the firm's progress and have very good information about a firm's investment prospects. This is a very demanding requirement in a complex world where most of investors' time is quite properly allocated to other activities. To put it another way, our as sumption that the profitability of new investment is public information should not be taken literally - - it is meant to apply to the most sophisticated arbitrageur, rather than to the average investor. Thus to make the firm's investment decision depend on a majority vote of average investors would be rather like running the firm by a not very well informed committee - a procedure whose record of success historically has been less than outstanding.

For these reasons, our assumption that renegotiation is impossible seems more than plausible for widely-held corporations.

There are a number of possible extensions of the analysis. First, the assumption that the interest rate is deterministic could be relaxed and the number of periods could be increased to allow for the possibility that investment and financial structure today depend on the market's expectation of these choices tomorrow. A multiperiod analysis might also explain the existence of corporate securities other than debt or equity, such as options or convertibles. 36 In addition, a multiperiod analysis raises interesting new questions about the meaning of seniority. To mention one: in what sense does 
a bond issued at date 1 with a promise to pay one dollar at date 4 have priority over a bond issued at date 2 which promises to pay one dollar at date 3 ?

Second, the assumption that all uncertainty is resolved at date 1 could be dropped. One special feature of the present model is that high debt prevents the firm from financing a positive NPV project only when the firm's date 1 value of equity is zero $\left(r+y_{2}-d<i-y_{1}\right.$ and $\left.r>i-y_{1}+y_{2}<d\right)$. This is no longer true if some uncertainty remains at date 1 . For example, suppose $y_{1}-0, i-20$; and with probability $1 / 2, y_{2}-100, r-0$, and with probability $1 / 2, y_{2}=0, x-50$. Then if there is $\$ 70$ of (senior, undilutable) debt, the firm cannot finance its positive NPV project, and yet the date 1 value of equity is positive. ${ }^{37}$

Third, it is very desirable to make the treatment of bankruptcy more realistic. In this paper we have supposed that bankruptcy is a completely neutral event: the firm's position in bankruptcy is exactly the same as its position outside bankruptcy (management retains control over the assets and must operate within the firm's existing capital structure in both uses). 38 In future work it is important to develop a theory of bankruptcy which gives some power to creditors to liquidate assets and helps explain the flow of funds out of the firm as well as into the firm.

Finally, our analysis has completely ignored the role of shareholder voting and takeovers in a firm's choice of financial structure. Yet voting and takeovers are important restraining forces on management. In future work it is desirable to develop a theory that explains not only the priority structure associated with different types of claims but also these claims' control rights - - in particular, why debt, as well as being senior to equity, carries the right to liquidate the firm or force it into bankruptcy; while equity, which is junior to debt, has voting rights. 


\section{FOOTNOTES}

1Alternatively, the tax theory supposes that the tax authorities would classify debt as equity - - and cancel debt's tax-favored status - if the debt-equity ratio became too high.

${ }^{2}$ See Merton (1990).

${ }^{3}$ Exceptions are Harris-Raviv (1989) and Zender (1989). For a very good recent survey of market completion and control theories, see Allen (1990).

${ }^{4}$ This argument implicitly assumes that the firm cannot renegotiate with senior creditors to reduce the debt from above $\$ 100$ in the presence of positive NPV projects. In the conclusions, we argue that such renegotiation will be extremely difficult if the initial creditors form a dispersed group.

5 Our theory of the costs of high debt has common features with the recent literature on third-world debt. Sachs (1986), for example, has argued that one of the costs of high debt is "debt-overhang": a country with large debt may have difficulty attracting new investment funds since much of the benefit from new investment will go to old creditors. The same point has been made in the corporate context by Roe (1987), who argues that debt-overhang might have thwarted Chrysler's K-car project in the absence of government financing. These authors do not use this idea to develop a theory of capital structure, however.

Note that the theory presented here is consistent with another oft-quoted cost of financial distress: suppliers are unwilling to deal with a firm which is close to bankruptcy. The point is that suppliers, just like providers of capital, will be deterred because they have low priority in the claimant queue.

For evidence that the total costs of financial distress can be very significant, see Cutler and summers (1988).

${ }^{6}$ other papers which explicitly or implicitly assume that firms act on behalf of initial shareholders include Myers and Majluf (1984); and many of the contributions which argue that high debt is costly because it causes management to take excessively risky actions (see, e.g., Stiglitz (1972) or Jensen \& Meckling (1976)).

${ }^{7}$ It should also be noted that our theory explains both the costs and benefits of debt. Thus, unlike Myers, we do not need taxes to understand why firms choose an interior debt-equity ratio.

${ }^{8}$ For a model in which the threat by creditors to liquidate assets in the event of default forces a firm to pay out funds, see Hart and Moore (1989). 
9 Our neglect of bankruptcy and 1 iquidation distinguishes our analysis from the recent papers by Stulz (1990) and Xie (1990). Stulz and Xie consider models in which high short-term debt is good in that it forces management to pay out funds, but bad because it automatically leads to inefficient piecemeal liquidation in the event of default (with, in Stulz's case, a loss of investment opportunities): Stulz and Xie do not consider the possibility that high debt prevents the firm from raising new capital.

${ }^{10}$ The investment can be interpreted to include maintenance of plant and equipment, advertising or other marketing expenses, expenditures on raw materials, incorporation of new technology, and recruitment and training of employees (as in Myers (1977)).

11 Not that this position is consistent with the idea that there is a reallocation of claims from equity-holders to creditors in bankruptcy. The important point is that the firm's operations - including its overall financial structure - - do not change.

12 This means that the corporate charter could not, for example, state that the firm may borrow one million dollars at date 1 , but only if $y_{2}$ exceeds two million dollars; this is unenforceable.

13

This assumption could be relaxed.

14 Not forcing management to pay out of their own pocket for the (nonpecuniary) benefits they will later receive from the firm's investment project; one justification for this is that management has no (or little) initial wealth.

15 That is, authorized share capital equals issued share capital.

${ }^{16}$ This implicitly assumes that any funds raised by issuing more debt do not affect $P$. In fact, of course, the new funds will be used to finance investment, and so $P$ will rise. Hence class $i$ creditors may benefit from the dilution. 
17 This is a case where there is an obvious potential role for short-term debt to force the manager to pay out funds at date 1 (see our earlier discussion in the Introduction and Section 2).

${ }^{18}$ One point to observe about Proposition 3: the debt $y_{1}+y_{2}$ is riskless.

However, the fact that it is riskless does not mean that it isn't playing an important role in preventing the manager from making unprofitable investments. We discussed a similar example in the Introduction.

${ }^{19} \mathrm{~T}$ optimal security structures in Propositions 1 and 2 were also simple debt/equity, with $d_{1}-0$ and $d_{1}-\infty$ respectively.

${ }^{20}$ There is virtually no loss of generality here: any finite discrete support of rational numbers is a subset of some uniform (integer) grid, provided the units of measurement are chosen appropriately. If one or more of the realisations of $y_{1}, y_{2}, i$ or $r$ happens to be irrational, then an arbitrarily close rational could be substituted in such a way as to preserve the inequalities $\mathrm{N}\left(\mathrm{r}+\mathrm{y}_{2}\right) \geq i-\mathrm{y}_{1}$.

${ }^{21}$ Simply replace $\mathrm{N}($.$) by its integer part. The two constraints on \mathrm{N}($.$) ,$ (2.2) and (2.3), will be unaffected.

${ }^{22}$ Notice the $1+\mathrm{N}\left(\mathrm{r}+\mathrm{y}_{2}\right)$, as opposed to simply $\mathrm{N}\left(\mathrm{r}+\mathrm{y}_{2}\right)$, in the range of integration. This reflects the fact that $N($.$) is the old security structure$ - i.e. prior to the increase in $n_{P}$.

${ }^{23}$ Conditions (2.2) and (2.3) ensure that the qualifier $\dot{\mathrm{P}}-\mathrm{P} \geq \hat{\mathrm{N}}-\mathrm{N} \geq 0$ in Condition $K$ will be satisfied by $K(P, N(P))$. 
${ }^{24}$ It is useful to note the following variant of proposition 4: If $y_{1}$ and $i$ are both deterministic, then (4b) can be dispensed with. The reason is that new investment occurs iff $N(P) \geq 1-y_{1}, 1$.e., in view of (2.3), iff $P \geq$ some $P^{c}$. It follows that the optimum can be sustained by a simple debt/equity structure with $d-P^{c}-\left(i-y_{1}\right)$. There are many other ways of achieving the optimum, however; this explains the apparent inconsistency between Proposition 4 and Example 1 when $i$ is deterministic.

${ }^{25}$ In fact, condition ( 4 a) of proposition 4 can be relaxed. It is enough that $i$ is independent of $\left(\mathrm{r}^{\mathrm{y}} \mathrm{y}_{2}\right)$ $y_{1}=i+u$, where $u$ is independent of $i$ $\left(r+y_{2}\right)$ is a sufficient statistic for $r$ in the presence of $u$.

The point is that, under these weaker assumptions, $K(P, N)$ is still independent of $\mathrm{N}$.

${ }^{26}$ Again, condition ( $5 a$ ) of proposition 5 can be relaxed. It is enough that

$r$ is independent of $\left(i-y_{1}\right)$

$\left(5 a^{\prime}\right) \quad y_{2}-v-r$, where $v$ is independent of $r$

$\left(y_{1}-i\right)$ is a sufficient statistic for $i$ in the presence of $v$.

We do not give a formal proof of Proposition 5, since it is similar to the proofs of the Lemma and Proposition 4 - with Condition $K$ replaced by: $K(P, N)$ independent of $P$ and decreasing in $N$.

27

27 Although as in ( $\left.4 \mathrm{a}^{\prime}\right)$ and $\left(5 \mathrm{a}^{\prime}\right)$ above, full independence can be relaxed to: $r+y_{2}$ is a sufficient statistic for $r$ in the presence of $i-y_{1}$; and $i-y_{1}$ is a sufficient statistic for $i$ in the presence of $r+y_{2}$.

${ }^{28}$ We are glossing over a technicality here. As defined, the distributions $F_{1}{ }^{m}, F_{2}{ }^{m}, F_{1}^{m}, F_{r}^{m}$ are continuous, whereas our analysis has been carried out for the case of finite distributions. To be rigorous, therefore, Proposition 7 should be stated for finite distributions which are approximations to $F_{1}{ }^{m}$, $\mathrm{F}_{2}{ }^{\mathrm{m}}, \mathrm{F}_{\mathrm{i}}{ }^{\mathrm{m}}, \mathrm{F}_{\mathrm{r}}^{\mathrm{m}}$ (in the weak convergence topology) and for which condition $\mathrm{K}$ holds. (Finite approximations with these properties can be chosen.) For such finite approximations, a simple debt/equity structure will be optimal. 
${ }^{29}$ In treating $F$ as continuous, we are glossing over various technicalities. To be rigorous, all the results of this section should be stated for finite distributions which approximate the continuous distributions (in the weak convergence topology) and for which Condition $K$ holds.

For these finite approximations, we know that simple debt/equity is optimal (since $\mathrm{K}$ holds). In addition, the optimal debt level is given approximately by the solution to (3.2). To see this, consider first the case where the limiting distribution is bounded (as in the uniform case). Then for the finite approximations $d$ is characterized by the pair of inequalities (FOCl) at $P-d+\epsilon$ and $(F O C 2)$ at $P-d$, where in both inequalities $N\left(r+y_{2}\right)=$ $\max \left(0, r+y_{2}-d\right)$ and $\epsilon$ is the size of the (integer) grid. As the finite approximation converges to the continuous limit, standard arguments (see Parthasarathy (1967)) show that any solution to (FOC1) and (FOC2) must converge to the solution to (3.2) (which, generically, is unique in the uniform case for an interior optimum). It follows that all the comparative statics properties established for the continuous case also hold for the finite approximations.

A slightly different argument is required for the normal case since the limiting distribution is unbounded. For each $\mathrm{m}$, choose finite distributions for the random variables $\mathrm{y}_{1}, \mathrm{y}_{1}, i, \mathrm{r}$ wich approximate the normal distributions $\mathrm{N}\left(\mu_{1}, \sigma_{1}^{2}\right), \mathrm{N}\left(\mu_{2}, \sigma_{2}^{2}\right), \mathrm{N}\left(\mu_{i}, \sigma_{i}^{2}\right), \mathrm{N}\left(\mu_{\mathrm{r}}, \sigma_{\mathrm{r}}^{2}\right)$ in the weak convergence topology, whose supports are $(-m, \infty)$, and for which Condition $K$ is satisfied when $m$ is large. Replace $y_{1}, y_{2}, i, r$ by $\left(y_{1}+m\right),\left(y_{2}+m\right),(i+m),(r+m)$, respectively.

Then simple debt/equity is optimal for a firm characterized by the independently distributed random variables $\left(y_{1}+m\right),\left(y_{2}+m\right),(i+m),(r+m)$.

Moreover, if we denote the optimal debt level by $d$, it is straightforward to show that ( $d-2 m$ ) converges to the solution to ( 3.2 ) (which is unique in the normal case). It follows again that the comparative statics properties established for the continuous normal case hold for the finite approximations.

${ }^{30}$ Notice that $s_{2}, s_{r}$ are $\sqrt{3}$ times the standard deviations of $y_{2}$ and $r$ respectively. 
${ }^{31}$ Much the same analysis would go through if we dropped the assumption that $s_{r}$ $<s_{2}$. But then there would be three possibilities to consider:

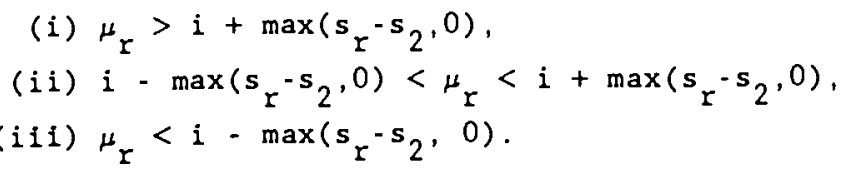

Case (a) above corresponds to (i); case (b) to (iii); and (ii) cannot hold if $s_{r}<s_{2}$. When $s_{r}>s_{2}$, some of the comparative statics effects we derive in the text - - In particular those concerning variances - - do not hold for the "middle" possibility (ii). This is not surprising, in that as we shall see these effects change sign in moving from case (a) (new investment is on average profitable) to case (b) (new investment is on average unprofitable). For this reason, when $s_{r}>s_{2}$, certain statements that follow in the text must be qualified by: ".. if the average return to new projects is sufficiently positive" (i.e. (i) holds); or "... if the average return to new projects is sufficiently negative" (i.e. (iii) holds).

${ }^{32}$ The uniformity assumption means that all points in the rectangle are equally likely. And the assumption $s_{r}<s_{2}$ means that the rectangle is wider than it is taller, so that the $135^{\circ}$ line cannot intersect both vertical sides. Moreover for the optimal d it cannot intersect both horizontal sides either, for then the LHS of (3.2) (a) would equal $\mu_{r}-i>0$.

${ }^{33}$ One additional point to note from Example 3 . Provided we can be sure that simple debt/equity remains an optimal security structure, it isn't essential that $y_{1}$ and $i$ are deterministic. All that matters for the purposes of the example is that $\left(y_{1}+y_{2}\right)$ and $(r-i)$ are independent and uniformly distributed. (Even a degree of positive correlation could be readily incorporated; as we have already suggested, such correlation would be natural if there is some exogenous uncertainty which commonly affects the returns to existing assets and the profitability of new investment.) This suggests the following extension to our discussion of the variances: if new investment is on average profitable [resp. unprofitable], then the optimal debt level rises as the variance of $i$ rises [resp. falls] or the variance of $y_{1}$ falls [resp.

rises]. 
${ }^{34}$ For a further discussion of the free-rider problem, see Roe (1987), and for a recent formal analysis, see Mailath and Postlewaite (1988). For evidence that breakdowns occur in practice, see Gilson, John and Lang (1990).

${ }^{35}$ See Roe (1987).

${ }^{36}$ Options and convertibles - - and also preferred shares - - correspond to particular $N(P)$ functions (see Section 2), but they do not have an

independent role since any $N(P)$ function can be sustained solely by different combinations of debt. That is, our analysis is consistent with, but does not explain, options, convertibles, or preferred shares.

37 . 37. The presence of uncertainty at date $1 \mathrm{might}$ also lead to a distortion in the project; for example, the manager might find it easier to finance an excessively risky project than a less risky, but more profitable, one.

${ }^{38}$ In a sense, we have steered a middle course between two extreme 'positions on bankruptcy: the pessimistic view, that bankruptcy leads to inefficient piecemeal liquidation of assets; and the optimistic view, that bankruptcy procedure provides a forum for parties to renegotiate their claims (including these claims' seniority) so that efficient liquidation and investment decisions are made. Neither extreme is compelling. The pessimistic view seems too pessimistic given that bankruptcy procedure (particularly. Chapter 11) is explicitly designed to prevent inefficient liquidation. On the other hand, the optimistic view appears to imply that it is efficient for firms to spend much or all of their time in bankruptcy; a conclusion that is hard to stomach. 
In this Appendix, we prove the Lemma, Propositions 6 and 8 , and obtain formulae for debt and equity values in Example 3.

Proof of Lemma

Take any optimal security structure represented by $N($.$) . Unless this$ security structure happens to be simple debt/equity (in which case the lemma holds), there must be at least one $P$ such that $n_{P}-1$ and $n_{p+1}-0$. Now proceed with the following algorithm:

For each $\mathrm{p}$ such that $n_{\mathrm{P}}-1$ and $n_{\mathrm{P}+1}-0$, ask:

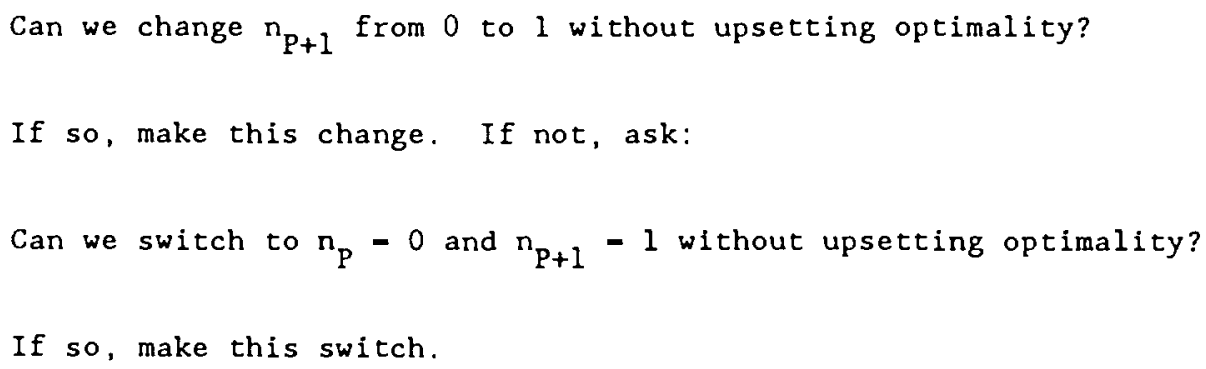

Continue to make such adjustments to $\mathrm{N}($.$) until no more can be made.$ Notice that the algorithm must stop somewhere, since the net effect of changing any $n_{P+1}$ from 0 to 1 is to reduce the total number of zeros in the (finite) sequence of $n^{\prime} s$; and this cannot cycle. Equally, the net effect of switching any $\left(n_{p}, n_{p+1}\right)$ from $(1,0)$ to $(0,1)$ is to shuffle the zeros towards the start of the (finite) sequence of $n^{\prime} s$; and this too cannot cycle.

The idea of the algorithm is this. Either it will stop at a point where there are no $\mathrm{P}^{\prime}$ s left such that $\mathrm{n}_{\mathrm{P}}-1$ and $\mathrm{n}_{\mathrm{P}+1}-0$; in which case we will have arrived at an optimal simple debt/equity security structure and the lemma holds. Or it will stop at a point where for some $P$, not only does $n_{p}-$ 1 and $n_{\mathrm{P}+1}-0$, but also (FOC3) strictly applies at $P$ and (FOC2) strictly applies at $\mathrm{P}+1$; i.e., 


$$
\begin{gathered}
\mathrm{K}(\mathrm{P}, \mathrm{N}(\mathrm{P}))>0 \\
\text { and } \\
\int(\mathrm{r}-\mathrm{i}) \mathrm{dF}\left(\mathrm{y}_{1}, \mathrm{y}_{2}, \mathrm{i}, \mathrm{r}\right)<0 \\
\begin{array}{c}
\mathrm{I}+\mathrm{N}\left(\mathrm{r}+\mathrm{y}_{2}\right)-\mathrm{i}-\mathrm{y}_{1} \\
\mathrm{r}+\mathrm{y}_{2} \geq \mathrm{P}+1
\end{array}
\end{gathered}
$$

We now use Condition $K$ to show that these two strict inequalities are inconsistent.

Since $n_{P+1}-0$, we know that $1+N(\hat{P})-N(P) \leq \hat{P}-P$ for $\hat{P} \geq P+1$. Combining this with $(F O C 3 *)$, we can apply Condition $K$ (putting $N-N(P)$ ) to deduce that $K(P, N) \geq 0$ for $\hat{P} \geq P+1$ and $\hat{N}-1+N(P)$. But then the LHS of (FOC2*), which can be written

$$
\begin{aligned}
& \sum_{\hat{P} \geq P+1} K(\hat{P}, \hat{N}) \times \operatorname{Prob}\left(r+y_{2}-\hat{P} \& i-y_{1}-\hat{N}\right), \\
& \hat{N}=1+N(\hat{P})
\end{aligned}
$$

is nonnegative, a contradiction.

Q.E.D.

\section{Proof of Proposition 6}

Consider a pair $(P, N)$ such that Prob $\mid r+y_{2}-P$ and $\left.i-y_{1}-N\right)>0$. It is straightforward to confirm that

$$
E\left[r \mid r+y_{2}-P\right]-\frac{1}{2} \max \left(\underline{r}, P \cdot \bar{y}_{2}\right)+\frac{1}{2} \min \left(\bar{r}, P-y_{2}\right\}
$$




$$
\text { and } E\left[1 \mid i-y_{1}-N\right]-\frac{1}{2} \max \left(\underline{i}, y_{1}+N\right)+\frac{1}{2} \min \left(\bar{I}, \bar{y}_{1}+N\right)
$$

Note that $\frac{\partial}{\partial P} E\left[r \mid r+y_{2}-P\right] \geq \frac{1}{2}-$ unless there exists a $P$ such that

$$
\begin{aligned}
& P-\bar{y}_{2}<\underline{r} \text { and } P-y_{2}>\bar{r}_{1} \\
& \text { or } \bar{r}+y_{2}<P<\underline{r}+\bar{y}_{2},
\end{aligned}
$$

which is impossible since by assumption $\bar{r}-\underline{r} \geq \bar{y}_{2}-\underline{y}_{2}$.

Also note that $\frac{\partial}{\partial N} E\left[i \mid i-y_{1}=N\right] \leq \frac{1}{2}$. unless there exists an $N$ such that

$$
\begin{aligned}
& y_{1}+N>i \text { and } \vec{y}_{1}+N<\vec{i}, \\
& \text { or } \quad \quad \quad i-y_{1}<N<\vec{i} \cdot \bar{y}_{1},
\end{aligned}
$$

which is impossible since by assumption $\bar{i}-\underline{i} \leq \bar{y}_{1}-y_{1}$.

We therefore conclude that $\frac{\partial}{\partial P} E\left[r \mid r+y_{2}-P\right] \geq \frac{1}{2} \geq \frac{\partial}{\partial N} E\left[i \mid i-y_{1}=N\right]$. This means that Condition $K$ is satisfied. Now apply the Lema.

Q.E.D.

\section{Proof of Proposition 8}

Denote the LHS of $(3.2 a)$ by $G(d)$. The first half of Condition $c$ tells us that

(A. 1)

$$
0 \leq G^{\prime}(d) \leq 1
$$


Typically, then, there will be a unique solution to ( $3.2 a)$. Moreover, if some change in parameter of $F\left(y_{1}, y_{2}, i, r\right)$ causes the function $G($.$) to rise, then d$ will have to fall in order to restore optimality (i.e. to restore the equality $G(d)-0$ ); and vice versa.

\section{A rise in the mean of $r$}

Consider shifting the distribution $r$ one unit to the right (implying a rise in the mean of $r$, but no change in the variance). For a given $d$, this will change the LHS of $(3.2 a)$ to

$$
\begin{gathered}
E\left[r+1-i \mid r+1-i+y_{1}+y_{2}-d \& i \geq y_{1}\right] \\
-1+E\left[r-i \mid r-i+y_{1}+y_{2}-d-1 \& i \geq y_{1}\right] \\
-1+G(d-1) \geq G(d) \quad \text { by }(A .1)
\end{gathered}
$$

- where this $G($.$) is the old G$ (prior to the shift in $r$ ). To restore optimality, d must therefore fall.

\section{A rise in the mean of $\mathrm{y}_{2}$}

Consider shifting the distribution $y_{2}$ one unit to the right (implying a rise in the mean of $y_{2}$, but no change in the variance). For a given d, this will change the LHS of ( $3.2 a)$ to

$$
\begin{aligned}
& E\left[r-i \mid r-i+y_{1}+1+y_{2}-d \& i \geq y_{1}\right] \\
& -G(d-1) \leq G(d) .
\end{aligned}
$$

- where this $G($.$) is the old G$ (prior to the shift in $y_{2}$ ). To restore optimality, d must therefore rise (in fact, rise by one unit). 
To obtain similar results for shifts in the means of $i$ and $y_{1}$, observe that ( $3.2 b)$ can be expressed:

$$
\left.H(d, \hat{d})\right|_{\hat{d}=d}-0,
$$

where $H(d, \hat{d})=E\left[r-i \mid r-i+y_{1}+y_{2}-d \& r+y_{2} \geq \hat{d}\right]$. The second half of condition $C$ tells us that

$$
0 \leq \frac{\partial H}{\partial d}(d, \hat{d}) \leq 1 .
$$

We can now proceed with:

\section{A rise in the mean of $i$}

Consider shifting the distribution of $i$ one unit to the right (implying a rise in the mean of $i$, but no change in the variance). For a given $d$, this will change the LHS of ( $3.2 b)$ to

$$
\begin{aligned}
& E\left[r-i-1 \mid r-i-1+y_{1}+y_{2}-d \& r+y_{2} \geq d\right] \\
& =\quad-1+E\left[r-i \mid r-i+y_{1}+y_{2}=d+1 \& r+y_{2} \geq d\right] \\
& =\quad-1+H(d+1, d)
\end{aligned}
$$

by $(A .2) \leq H(d, d)-G(d)$.

- where these $G($.$) and H($.$) are the \underline{O l d} G$ and $H$ (prior to the shift in i). To restore optimality, d must therefore rise. 
A rise in the mean of $y_{1}$

Consider shifting the distribution of $y_{1}$ one unit to the right (implying a rise in the mean of $y_{1}$, but no change in the variance). For a given $d$, this will change the LHS of $(3.2 \mathrm{~b})$ to

$$
\begin{aligned}
& \quad E\left[r-i \mid r-i+y_{1}+1+y_{2}-d \& r+y_{2} \geq d\right] \\
& -\quad H(d-1, d) \\
& \text { by (A.2) } \leq H(d, d)=G(d) .
\end{aligned}
$$

- where these $G($.$) and H($.$) are the old G$ and $H$ (prior to the shift in $y_{1}$ ). To restore optimality, d must therefore rise.

Q.E.D.

Computation of debt and equity values in Example 3

Case (a): $\mu_{r}>$ i. Ex post (i.e. at dates 1 and 2), the value of debt $d$ equals

$$
\begin{cases}d & \text { if either }\left(y_{1}+y_{2}\right) \geq d \text { or }(r-i)+\left(y_{1}+y_{2}\right) \geq d \\ y_{1}+y_{2} & \text { otherwise. }\end{cases}
$$

From Figure 4 it follows that the ex ante (date 0 ) value of debt is given by 


$$
\begin{aligned}
& v(d)=\iint\left[y_{1}+y_{2}\right\rfloor \partial F\left(y_{2}, r\right)+\iint[d] \partial F\left(y_{2}, r\right) \\
& \mu_{2}-s_{2} \leq y_{2}<d-y_{1} \quad \mu_{2}-s_{2} \leq y_{2}<d-y_{1} \\
& r<d-\left(y_{1}+y_{2}\right)+i \quad r \geq d-\left(y_{1}+y_{2}\right)+i \\
& +\quad \iint[d] \partial F\left(y_{2}, r\right) \\
& \mathrm{d}-\mathrm{y}_{1} \leq \mathrm{y}_{2} \leq \mu_{2}+\mathrm{s}_{2} \\
& \text { all } r
\end{aligned}
$$

-. where $F\left(y_{2}, r\right)$ is the distribution function of $\left(y_{2}, r\right)$. It is straightforward but tedious to show that, given $d-y_{1}+\mu_{2}-s_{2}-\mu_{r}+s_{r}+i$,

$$
v(d)=y_{1}+\mu_{2}-s_{2}-\mu_{Y}+s_{Y}+i+\frac{5\left(\mu_{Y}-s_{Y}-i\right)^{3}}{24 s_{2} s_{r}} \text {. }
$$

The total value of (debt + equity) equals the expected return from existing assets, $y_{1}+\mu_{2}$, plus the expected return from new investment. That is, if the value of equity is $v(e)$,

$$
\begin{gathered}
v(d)+v(e)-y_{1}+\mu_{2}+\iint y_{2}[r-i] \partial F\left(y_{2}, r\right) \\
-y_{1}+\mu_{2}+\mu_{r}-i-\frac{\left(\mu_{r}-s_{r}-1\right)^{3}}{6 s_{2} s_{r}} .
\end{gathered}
$$

Hence 


$$
v(e)-2\left(\mu_{r}-i\right)+s_{2}-s_{r}-\frac{3\left(\mu_{r}-s_{r}-i\right)^{3}}{8 s_{2} s_{r}}
$$

Now it is a straightforward matter to confirm the comparative statics properties in Table 2 in the text, where we use our assumptions: $s_{r}<s_{2}, \mu_{r}$ $>i$ and $\mu_{r}^{-s_{r}}<i$. (That is: $0<-\left(\mu_{r^{-}}-s_{r}^{-i}<s_{r}<s_{2}\right.$.)

Case (b) : $\mu_{r}<1$. Reasoning much as in case (a), we can show that

$$
\begin{aligned}
& v(d)-y_{1}+\mu_{2}+\frac{\left(\mu_{r}-i+s_{r}\right)^{2}\left(\mu_{r}-i-5 s_{r}\right)}{24 s_{2} s_{r}} ; \text { and } \\
& v(e)=\frac{\left(\mu_{r}-i+s_{r}\right)^{2}\left(\mu_{r}-i+3 s_{r}\right)}{8 s_{2} s_{r}} .
\end{aligned}
$$

The comparative statics properties in Table 3 in the text can easily be confirmed. 
Aghion, P. and P. Bolton (1988), "An 'Incomplete Contract' Approach to Bankruptcy and the Financial structure of the Firm", Technical Report 536, IMSSS, Stanford University.

Allen, F. (1990), "The Changing Nature of Debt and Equity: A Financial Perspective," in Are the Distinctions Between Debt and Equity Disappearing?, R. Kopcke and E. Rosengren (eds.), Federal Reserve Bank of Boston Conference Series No. 33, pp. 12-38.

Allen, F. and D. Gale (1988), "Optimal Security Design", Review of Financial Studies, 1:229-263.

Bolton, P. and D. Scharfstein (1990), "A Theory of Predation Based on Agency Problems in Financial Contracting", American Economic Review, March, $1990,93-106$.

Brealey, R. and S. Myers (1988), Principles of Corporate Finance, McGraw-Hill, 3rd Edition.

Cutler, D. and L. Sumers (1988), "The Costs of Conflict Resolution and Financial Distress: Evidence from the Texaco-Pennzoil Litigation", Rand Journal of Economics, Summer, 157-172.

Diamond, D. (1989), "Debt Maturity Structure and Liquidity Risk", University of Chicago (mimeo).

Donaldson, G. (1984), Managing Corporate Wealth, New York: Praeger, 1984.

Gilson, S., John, K. and L. Lang (1990), "Troubled Debt Restructurings: An Empirical Study of Private Reorganization of Firms in Default", mimeo, N.Y.U.

Grossman, S. and O. Hart (1982), "Corporate Financial Structure and Managerial Incentives", in J.J. McCall, ed., The Economics of Information and Uncertainty, University of Chicago Press.

Harris, M. and A. Raviv (1989), "The Design of Securities", Working paper, Graduate School of Business, University of Chicago.

Hart, O. and J. Moore (1989), "Default and Renegotiation: A Dynamic Model of Debt", MIT Dept. of Economics Working Paper.

Jensen, M. (1986), "Agency Costs of Free Cash Flow, Corporate Finance and Takeovers", American Economic Review, 76:323-329.

Jensen, M. and W. Meckling (1976), "Theory of the Firm: Managerial Behavior, Agency Costs and Ownership Structure", Journal of Financial Economics, $3: 305-360$ 
Kester, W. (1986). "Capital and Ownership Structure: A Comparison of United States and Japanese Manufacturing Corporations". Einanclal Management, Spring, pp 5-16.

Leland, H. and D. Pyle (1977), "Informational Asymmetries, Financial Structure, and Financlal Intermediation", Journal of Finance, 32, 2.

Mailath, G. and A. Postlewaite (1988), "Workers versus Firms: Bargaining Over a Firm's Value", mimeo, University of Pennsylvania.

Marris, R. (1964), The Economic Theory of Managerial Capitalism, Illinois: Free Press of Glencoe.

Merton, R. (1990), "The Changing Nature of Debt and Equity: Discussion" in Are the Distinctions Between Debt and Equity Disappearing?, R. Kopcke and E. Rosengren (eds.), Federal Reserve Bank of Boston Conference Series No. 33, pp. 44-48.

Miller, M. (1977), "Debt and Taxes", Journal of Finance, 32 (May):261-275.

Modigliani, F. and M. Miller (1963), "Corporate Income Taxes and the Cost of Capital: A Correction", American Economic Review, 53:433-443.

Myers, S. (1977), "Determinants of Corporate Borrowing", Journal of Financial Economics, 5 (November):147-175.

Myers, S. (1990), "Still Searching for Optimal Capital Structure", in Are the Distinctions Between Debt and Equity Disappearing?, R. Kopcke and E. Rosengren (eds.), Federal Reserve Bank of Boston Conference Series No. 33.

Myers, S. and N. Majluf (1984), "Corporate Financing and Investment Decisions When Firms Have Information That Investors Do Not Have", Journal of Financial Economics, $13: 187-221$.

Parthasarathy, K. (1967), Probability Measures on Metric Spaces, Academic Press.

Roe, M. (1987), "The Voting Prohibition in Bond Workouts", Yale Law Journal, $97: 232-279$.

Ross, S. (1977), "The Determination of Financial Structure: The Incentive Signalling Approach", Bell Journal of Economics, 8:23-40.

Sachs, J. (1986), "Managing the LDC Debt Crisis", Brookings Papers on Economic Activity, .

Stiglitz, J. (1974), "On the Irrelevance of Corporate Financial Policy", American Economic Review, 64 .

(1972), "Some Aspects of the Pure Theory of Corporate Finance: Bankruptcies and Take-Overs," Bell Journal of Economics and Management Science, $3(2): 458 \cdot 482$. 
Stulz, R. (1990), "Managerial Discretion and Capital Structure", Ohio State Universicy (mimeo).

Warner, J. (1977), "Bankruptcy Costs: Some Evidence", Journal of Finance, $32: 337-347$.

Xie, G. (1990), "Essays on the Theory of the Firm", unpublished PhD dissertation, MIT

Zender, J. (1989), "Optimal Financial Instruments", Working paper, University of Utah. 